University of Wollongong

Research Online

Faculty of Engineering and Information

Faculty of Engineering and Information

Sciences - Papers: Part A

Sciences

$1-1-2013$

Improving the critical speeds of high-speed trains using

magnetorheological technology

Shuaishuai Sun

University of Wollongong, ss886@uowmail.edu.au

Huaxia Deng

Hefei University of Technology

Weihua Li

University of Wollongong, weihuali@uow.edu.au

Haiping Du

University of Wollongong, hdu@uow.edu.au

Yi Qing Ni

Hong Kong Polytechnic University

See next page for additional authors

Follow this and additional works at: https://ro.uow.edu.au/eispapers

Part of the Engineering Commons, and the Science and Technology Studies Commons

Research Online is the open access institutional repository for the University of Wollongong. For further information contact the UOW Library: research-pubs@uow.edu.au 


\title{
Improving the critical speeds of high-speed trains using magnetorheological technology
}

\begin{abstract}
With the rapid development of high-speed railways, vibration control for maintaining stability, passenger comfort, and safety has become an important area of research. In order to investigate the mechanism of train vibration, the critical speeds of various DOFs with respect to suspension stiffness and damping are first calculated and analyzed based on its dynamic equations. Then, the sensitivity of the critical speed is studied by analyzing the influence of different suspension parameters. On the basis of these analyses, a conclusion is drawn that secondary lateral damping is the most sensitive suspension damper.

Subsequently, the secondary lateral dampers are replaced with magnetorheological fluid (MRF) dampers. Finally, a high-speed train model with MRF dampers is simulated by a combined ADAMS and MATLAB simulation and tested in a roller rig test platform to investigate the mechanism of how the MRF damper affects the train's stability and critical speed. The results show that the semi-active suspension installed with MRF dampers substantially improves the stability and critical speed of the train.
\end{abstract}

\section{Keywords}

technology, magnetorheological, trains, improving, speed, critical, high, speeds

\section{Disciplines}

Engineering | Science and Technology Studies

\section{Publication Details}

Sun, S., Deng, H., Li, W., Du, H., Ni, Y. Qing., Zhang, J. \& Yang, J. (2013). Improving the critical speeds of high-speed trains using magnetorheological technology. Smart Materials and Structures, 22 (11), 1-14.

\section{Authors}

Shuaishuai Sun, Huaxia Deng, Weihua Li, Haiping Du, Yi Qing Ni, Jin Zhang, and Jian Yang 


\title{
Improving the Critical Speeds of High-Speed Train Using
}

\section{Magnetorheological Technology}

\author{
Shuaishuai Sun ${ }^{\mathrm{a}, \mathrm{b}}$, Huaxia Deng ${ }^{\mathrm{b} *}$, Weihua $\mathrm{Li}^{\mathrm{a}^{* *}}$, Haiping Du${ }^{\mathrm{c}}$, Yi Qing Ni ${ }^{\mathrm{d}}$, Jin Zhang ${ }^{\mathrm{b}}$, \\ Jian Yang ${ }^{a}$ \\ ${ }^{a}$ School of Mechanical, Material and Mechatronic Engineering, University of Wollongong, New South \\ Wales, 2522, Australia \\ ${ }^{b}$ School of Instrument Science and Opto-electronics Engineering, HeFei University of Technology, \\ Heifei, China \\ ${ }^{c}$ School of Electrical, Computer and Telecommunications Engineering, University of Wollongong, New \\ South Wales, Australia \\ ${ }^{d}$ Department of Civil and $S^{l}$ tructural Engineering, The Hong Kong Polytechnic University, Hung Hom, \\ Kowloon, Hong Kong
}

\begin{abstract}
With the rapid development of high-speed railways, vibration control for maintaining stability, passenger comfort, and safety has become an important area of research. In order to investigate the mechanism of train vibration, the critical speeds of various DOF with respect to suspension stiffness and damping are first calculated and analyzed based on its dynamics equations. Then, the sensitivity of critical speed is studied by analyzing the influence of different suspension parameters. Upon on these analyses, conclusion is drawn that secondary lateral damping is the most sensitive suspension damper. Subsequently, the secondary lateral dampers are replaced with magnetorheological fluid (MRF) dampers. At last, a high-speed train model with MRF dampers is simulated by a combination simulation of ADAMS and MATLAB and tested in a roller rig test platform to investigate the mechanism of how the MRF damper affects the train's stability and critical speed. The results show that the semi-active suspension installed with MRF damper substantially improves the stability and critical speed of the train.
\end{abstract}

Keywords:

High-speed train, Critical speeds, Magnetorheological fluid (MRF) damper, Simulation, roller rig experimental platform

\section{Introduction}

High-speed trains are an efficient solution of the demand for high speed transportation in a globalized economy. Compared with other forms of transportation, high-speed

\footnotetext{
$1 *$ corresponding author. E-mail: hxdeng@hfut.edu.cn (Huaxia Deng)

**corresponding author. E-mail: weihuali@uow.edu.au (Weihua Li)
} 
trains stand out for they are friendlier to the environment, they have cheaper unit delivery costs and they are safer [1-3]. However, as the speed of the train increases, a big challenge occurs that the train-induced vibration and noise increases significantly, which may lead to a series of problems such as ride instability, environmental noise in the neighborhood, possible accumulated damage to buildings and premature fatigue failure of the vehicle body $[3,4]$.

Generally, two main reasons induce the high-speed train vibration: the resonance and instability of the vehicle/structure system. Resonance refers to the phenomenon that the external disturbance of the vehicle is equal or close to the natural frequency of the whole system. For solving this resonance issue, a well-designed passive damper is commonly used. However, the parameters of passive damper are fixed, which means that once the system is designed, the damper cannot be adjusted. Additionally, a fixed passive damper may become ineffective due to other phenomena such as instability of the vehicle which is speed dependent. When the train speed reaches a critical value, the amplitude of the train vibration grows exponentially with time and theoretically reaches infinity in a linear system. For the reason that this instability of the vehicle/structure system is intrinsic and independent of the excitation type, a conventional passive damper is inadequate to maintain the system stability [5]. It is therefore crucial to study the mechanism of this train instability and find a controllable damper that can address the issues.

The mechanism of instability at critical speeds has been an important research topic in developing high-speed vehicles. In early 1916, Carter develops an instability theory mainly investigating the mechanism of high-speed train instability. [6]. In his dynamic model, the bogie consists of two wheelsets which are rigidly mounted in a frame. Following his work, a number of researchers develop four or more DOF models to analyze the instability problem [7-9]. Wu found that the suspension has an important influence on ride stability [10]. Liu made a number of studies on the effects of coupling stiffness and damping coefficient on ride comfort [11]. Zeng investigates a method for predicting the linear and non-linear critical speeds of train. In his paper a 
17-DOF train model is established and then the influence of secondary lateral damping on its critical speed is presented [12]. In the published book by Zhang, a train model of $17 \mathrm{DOF}$ is proposed and qualitatively analysis about the influence of the stiffness and damping of the bogie on the critical speeds of train is given [13]. It is concluded from his analysis that the suspension parameter significantly impacts the critical speed of trains. Based on the above literatures, the stiffness and damping of train bogies has been recognized as the important parameters that affect the critical speed of trains, which means the effect of the suspension parameters on the critical speed should be paid more attention. However, these literatures only focus on one critical speed-the critical speed of the whole train and the fact is that most of the train DOFs exist critical speeds. One of the highlights of this paper is that all the critical speeds of train DOFs are considered. Researches on each DOF's critical speed reveal the different stability of each train components. This revelation offers guidance for the design of train suspension parameters.

As mentioned above, finding a controllable suspension to suppress the vibration in high speed trains becomes urgent. Apart from passive control, active control and semi-active control can also improve the system performances over a wide range of train speeds. However, the active control is largely limited for common use for its requirements of large control force, more power and complex control strategies.[14-15]. Furthermore, an active control strategy adds extra power into the train system, which poses a threat to the strain stability. Recently, semi-active control has gained considerable interests because it requires less energy and can adjust system parameters in real time [16-17]. Many researchers have done excellent jobs on semi-active control of railway vehicle [18-20]. Variable orifice dampers have mainly been considered to control train vibration. ONeill and Wale [21] have done some pioneer work on the use of semi-active suspension to improve the ride quality of trains, although at present, the composition of the oil cylinders and mechanical valves reduces the stability of variable orifice dampers and increases their maintenance costs.

Another method used to realize semi-active control is to place controllable fluids into 
the damper. Electrorheological (ER) fluids and magnetorheological (MR) fluids are two typical controllable fluids which can change from a free flowing viscous fluid into a semi-solid. Their composition without extra moving parts makes them simple and reliable. ER fluids are excited by high voltage, which limits its use in many areas because of safety concerns. Comparatively speaking, MR fluids only need a low voltage source to excite a magnetic field, which means a semi-active suspension with MR fluids is more suitable for high-speed trains. A Magnetorheological fluid (MRF) damper makes use of the unique characteristics of MR fluids whose mechanical properties can be quickly and reversely controlled by an external magnetic field. Thus, this material provides simple, quiet, rapid-response interfaces between electronic controls and mechanical systems. The performance of an MRF damper falls into two distinct states: the passive state (or off-state) and the active state (or on-state). The passive state is a situation where no magnetic field is present and the MR fluid behaves as a Newtonian fluid, but when an external magnetic field alters its rheology, the MR fluid changes its apparent viscosity, which is defined as the active state. In the event of a power supply or control system fails, the MR fluid damper can still function as a typical passive damper [22-23], which ensures its continuing reliability as a damper. MR technology has been widely used to suppress vibration [24-25]. The application of MR technology in the vehicle field has been reported by a few groups developing semi-active suspension systems for attenuating vibration in automobiles and car seats [26-27]. Wang and Liao did simulation and theoretical analysis in studying railway vehicles using MRF dampers [28-29]. However, research into the application of MR dampers in high-speed railway systems is very rare.

In this article, a dynamic model of a high-speed train is developed, including the train's dynamic equations. Based on this dynamic model and equations, the damping ratio of each train DOF is calculated. When the damping ratio reduces and crosses the zero line, the train becomes unstable and reaches its critical speed. Thus, the critical speeds of various train DOFs with respect to suspension stiffness and damping can be worked out. The sensitivity of a train's critical speed with respect to the suspension 
parameters are analyzed in this paper. The result reveals that the secondary lateral damper impacts the train's critical speed most. As a result, the secondary lateral damper which is the most influential damper is replaced with a controllable MRF damper to improve train stability. In order to investigate the effect of MRF dampers on train's critical speed, a high-speed train installed with MRF dampers is simulated by a combined simulation of ADAMS and MATLAB. Then the MRF dampers installed in a high-speed train are tested in a roller rig test platform to explore the effect of MRF damping on train stability.

\section{Mathematical model and calculation of train critical speeds}

Many other typical train mathematical models have been presented in existing literatures [28,12]. Liao [28] establishes a 17-DOF train model to study the effect of semi-active suspension on train stability. Liu [30] proposes four different train dynamic models with 17-DOF 19-DOF, 31-DOF, and 35-DOF respectively in his $\mathrm{PhD}$ thesis. However, considering all the DOFs for characterizing train dynamics is not necessary, instead, it makes the calculation procedure more complicated. On the other hand, many researchers put forward a train component dynamic model with less DOF. For example, Scheffel proposes an 8-DOF train wheelset model [8]. The main advantage of these component models is that they cannot reflect the dynamic

performance of the whole train. However, a 15-DOF model proposed by Garg [31] can effectively characterize the main dynamic performance, it is therefore a 15-DOF high-speed train dynamic model is adopted in this section. The damping ratio of each DOF, as well as the train critical speed is worked out based on the train dynamic equations.

\subsection{Analytical model of high-speed train}

As shown in Fig.1, the dynamic model established in this paper is a typical high-speed train containing front truck frame and rear truck frame. Each truck frame built in this paper contains primary suspension and secondary suspension. Primary suspension is the connecting component of wheelset and bogie frame. Secondary suspension is the connecting component of bogie frame and car body. The detailed structure of the 15 
DOF is illustrated in Table 1. The nomenclature used in developing the 15 DOF passenger vehicle model are defined in Table A.1 in the appendix. 2.2. The dynamic equations of motion for the wheelsets, truck frames, and car body are as follows:

\subsubsection{Car body dynamics}

The following equations are the car body dynamics characterized by the lateral $\left(y_{\mathrm{c}}\right)$, yaw $\left(\psi_{\mathrm{c}}\right)$, and roll $\left(\theta_{\mathrm{c}}\right)$ motions.

$$
\begin{aligned}
m_{\mathrm{c}} \ddot{y}_{\mathrm{c}}= & 2 C_{\mathrm{sy}} \dot{y}_{\mathrm{c}}-C_{\mathrm{sy}} \dot{y}_{\mathrm{t} 2}-K_{\mathrm{sy}} y_{\mathrm{t} 1}-C_{\mathrm{sy}} \dot{y}_{\mathrm{t} 1}-K_{\mathrm{sy}} y_{\mathrm{t} 2}+2 K_{\mathrm{sy}} y_{\mathrm{c}}-2 C_{\mathrm{sy}} h_{4} \dot{\theta}_{\mathrm{c}}-2 h_{4} K_{\mathrm{sy}} \theta_{\mathrm{c}} \\
I_{\mathrm{cz}} \ddot{\psi}_{\mathrm{c}}= & -K_{\mathrm{sy}} \psi_{\mathrm{t} 1}+K_{\mathrm{sy}} \psi_{\mathrm{t} 2}+\left(2 K_{\mathrm{sy}} l_{\mathrm{b}}^{2}+2 K_{\mathrm{sy}}\right) \psi_{\mathrm{c}}-C_{\mathrm{sy}} l_{\mathrm{b}} \dot{y}_{\mathrm{t} 1}+C_{\mathrm{sy}} l_{\mathrm{b}} \dot{y}_{\mathrm{t} 2}-K_{\mathrm{sy}} l_{\mathrm{b}} y_{\mathrm{t} 1}+K_{\mathrm{sy}} l_{\mathrm{b}} y_{\mathrm{t} 2} \\
& +2 C_{\mathrm{sy}} l_{\mathrm{b}}^{2} \dot{\psi}_{\mathrm{c}} \\
I_{\mathrm{cx}} \ddot{\theta}_{\mathrm{c}}= & \left(4 C_{\mathrm{sz}} b_{4}^{2}+2 C_{\mathrm{sy}} h_{4}^{2}\right) \theta_{\mathrm{c}}+\left(4 K_{\mathrm{sz}} b_{3}^{2}+2 K_{\mathrm{sy}} h_{4}^{2}\right) \theta_{\mathrm{c}}+C_{\mathrm{sy}} h_{4} \dot{y}_{\mathrm{t} 1}+C_{\mathrm{sy}} h_{4} y_{\mathrm{t} 2}+h_{4} K_{\mathrm{sy}} y_{\mathrm{t} 1} \\
& -2 C_{\mathrm{sy}} h_{4} y_{\mathrm{c}}+h_{4} K_{\mathrm{sy}} y_{\mathrm{t} 2}-2 h_{4} K_{\mathrm{sy}} y_{\mathrm{c}}
\end{aligned}
$$

\subsubsection{Truck dynamics}

The governing equations of the truck dynamics of high-speed trains can be

characterized by the lateral $\left(y_{\mathrm{t} i}\right)$, yaw $\left(\psi_{\mathrm{t} i}\right)$ motions, in which the subscript $i=1,2$ ( 1 is the leading truck and 2 is the trailing truck). The equations for the leading truck are as follows:

$$
\begin{aligned}
m_{\mathrm{t}} \ddot{y}_{\mathrm{t} 1}= & \left(2 K_{\mathrm{pd}}+2 K_{\mathrm{py}}+K_{\mathrm{sy}}\right) y_{\mathrm{t} 1}-C_{\mathrm{py}} \dot{y}_{\omega 1}-C_{\mathrm{py}} \dot{y}_{\omega 2}-C_{\mathrm{sy}} \dot{y}_{\mathrm{c}}-K_{\mathrm{sy}} y_{\mathrm{c}}+\left(2 C_{\mathrm{py}}+C_{\mathrm{sy}}\right) \dot{y}_{\mathrm{t} 1}-K_{\mathrm{sy}} l_{\mathrm{b}} \psi_{\mathrm{c}} \\
& -\left(K_{\mathrm{pd}}+K_{\mathrm{py}}\right) y_{\omega 1}-\left(K_{\mathrm{pd}}+K_{\mathrm{py}}\right) y_{\omega 2}+C_{\mathrm{sy}} h_{4} \dot{\theta}_{\mathrm{c}}-C_{\mathrm{sy}} l_{\mathrm{b}} \dot{\psi}_{\mathrm{c}}+h_{4} K_{\mathrm{sy}} \theta_{\mathrm{c}}-K_{\mathrm{sy}} l_{\mathrm{b}} \psi_{\mathrm{c}} \\
I_{\mathrm{tz}} \ddot{\psi}_{\mathrm{t} 1}= & 2 C_{\mathrm{py}} \dot{y}_{\omega 1}-2 C_{\mathrm{py}} \dot{y}_{\omega 2}+8 C_{\mathrm{py}} \dot{\psi}_{\mathrm{t} 1}-K_{\mathrm{sy}} \psi_{\mathrm{c}}+\left(4 K_{\mathrm{px}} b_{1}^{2}+8 K_{\mathrm{pd}}+8 K_{\mathrm{py}}+K_{\mathrm{sy}}\right) \psi_{\mathrm{t} 1} \\
& +\left(2 K_{\mathrm{pd}}+2 K_{\mathrm{py}}\right) y_{\omega 1}-\left(2 K_{\mathrm{pd}}+2 K_{\mathrm{py}}\right) y_{\omega 2}-2 b_{1}^{2} K_{\mathrm{px}} \psi_{\omega 1}-2 b_{1}^{2} K_{\mathrm{px}} \psi_{\omega 2}
\end{aligned}
$$

The equations for the trailing truck are as follows:

$$
\begin{aligned}
m_{\mathrm{t}} \ddot{y}_{\mathrm{t} 2}= & \left(2 K_{\mathrm{pd}}+2 K_{\mathrm{py}}+K_{\mathrm{sy}}\right) y_{\mathrm{t} 2}-C_{\mathrm{py}} \dot{y}_{\omega 3}-C_{\mathrm{py}} \dot{y}_{\omega 4}-C_{\mathrm{sy}} \dot{y}_{\mathrm{c}}-K_{\mathrm{sy}} y_{\mathrm{c}}+\left(2 C_{\mathrm{py}}+C_{\mathrm{sy}}\right) \dot{y}_{\mathrm{t} 2} \\
& -\left(K_{\mathrm{pd}}+K_{\mathrm{py}}\right) y_{\omega 3}-\left(K_{\mathrm{pd}}+K_{\mathrm{py}}\right) y_{\omega 4}+C_{\mathrm{sy}} h_{4} \dot{\theta}_{\mathrm{c}}+C_{\mathrm{sy}} l_{\mathrm{b}} \dot{\psi}_{\mathrm{c}}+h_{4} K_{\mathrm{sy}} \theta_{\mathrm{c}}+K_{\mathrm{sy}} l_{\mathrm{b}} \psi_{\mathrm{c}} \\
I_{\mathrm{tz}} \ddot{\psi}_{\mathrm{t} 2}= & 2 C_{\mathrm{py}} \dot{y}_{\omega 3}-2 C_{\mathrm{py}} \dot{y}_{\omega 4}+8 C_{\mathrm{py}} \dot{\psi}_{\mathrm{t} 2}+K_{\mathrm{sy}} \psi_{\mathrm{c}}+\left(4 K_{\mathrm{px}} b_{1}^{2}+8 K_{\mathrm{pd}}+8 K_{\mathrm{py}}+K_{\mathrm{sy}}\right) \psi_{\mathrm{t} 2} \\
& +\left(2 K_{\mathrm{pd}}+2 K_{\mathrm{py}}\right) y_{\omega 3}-\left(2 K_{\mathrm{pd}}+2 K_{\mathrm{py}}\right) y_{\omega 4}-4 b_{1}^{2} K_{\mathrm{px}} \psi_{\omega 3}-b_{1}^{2} K_{\mathrm{px}} \psi_{\omega 4}
\end{aligned}
$$




\subsubsection{Wheelset dynamics}

The high-speed train includes four wheelsets. Two of them are installed in the leading truck while the other two are installed in the trailing truck. The lateral $\left(y_{\omega i}, i=1-4\right)$ and yaw $\left(\psi_{\omega i}, i=1-4\right)$ motions are used to characterize the wheelsets dynamics. The lateral motions $\left(y_{\omega i}, i=1-4\right)$ of the governing equations of the wheelsets are given by:

$$
\begin{aligned}
m_{\omega 1} \ddot{y}_{\omega 1}= & {\left[C_{\mathrm{py}}+\left(2 f_{22}\right) / v\right] \dot{y}_{\omega 1}+\left(K_{\mathrm{c}}-2 f_{22}+K_{\mathrm{pd}}+K_{\mathrm{py}}\right) y_{\omega 1}-C_{\mathrm{py}} \dot{y}_{\mathrm{t} 1}+2 C_{\mathrm{py}} \dot{\psi}_{\mathrm{t} 1}+\left(2 K_{\mathrm{pd}}+2 K_{\mathrm{py}}\right) \psi_{\mathrm{t} 1} } \\
& -\left(K_{\mathrm{pd}}+K_{\mathrm{py}}\right) y_{\mathrm{t} 1} \\
m_{\omega 2} \ddot{y}_{\omega 2}= & {\left[C_{\mathrm{py}}+\left(2 f_{22}\right) / v\right] \dot{y}_{\omega 2}-C_{\mathrm{py}} \dot{y}_{\mathrm{t} 1}-2 C_{\mathrm{py}} \dot{\psi}_{\mathrm{t} 1}+\left(K_{\mathrm{c}}-2 f_{22}+K_{\mathrm{pd}}+K_{\mathrm{py}}\right) y_{\omega 2}-\left(2 K_{\mathrm{pd}}+2 K_{\mathrm{py}}\right) \psi_{\mathrm{t} 1} } \\
& -\left(K_{\mathrm{pd}}+K_{\mathrm{py}}\right) y_{\mathrm{t} 1} \\
m_{\omega 3} \ddot{y}_{\omega 3}= & {\left[C_{\mathrm{py}}+\left(2 f_{22}\right) / v\right] \dot{y}_{\omega 3}-\left(K_{\mathrm{pd}}+K_{\mathrm{py}}\right) y_{\mathrm{t} 2}+\left(K_{\mathrm{c}}-2 f_{22}+K_{\mathrm{pd}}+K_{\mathrm{py}}\right) y_{\omega 3}-C_{\mathrm{py}} \dot{y}_{\mathrm{t} 2}+2 C_{\mathrm{py}} \dot{\psi}_{\mathrm{t} 2} } \\
& +\left(2 K_{\mathrm{pd}}+2 K_{\mathrm{py}}\right) \psi_{\mathrm{t} 2} \\
m_{\omega 4} \ddot{y}_{\omega 4}= & {\left[C_{\mathrm{py}}+\left(2 f_{22}\right) / v\right] \dot{y}_{\omega 4}-\left(K_{\mathrm{pd}}+K_{\mathrm{py}}\right) y_{\mathrm{t} 2}-C_{\mathrm{py}} \dot{y}_{\mathrm{t} 2}-2 C_{\mathrm{py}} \dot{\psi}_{\mathrm{t} 2}+\left(K_{\mathrm{c}}-2 f_{22}+K_{\mathrm{pd}}+K_{\mathrm{py}}\right) y_{\omega 4} } \\
& -\left(2 K_{\mathrm{pd}}+2 K_{\mathrm{py}}\right) \psi_{\mathrm{t} 2}
\end{aligned}
$$

The yaw motions $\left(\psi_{\omega i}, i=1-4\right)$ of the governing equations of the wheelsets are given by:

$$
\begin{aligned}
& I_{\omega z} \ddot{\psi}_{\omega 1}=2 b_{1}^{2} K_{\mathrm{px}} \psi_{\omega 1}-2 b_{1}^{2} K_{\mathrm{px}} \psi_{\mathrm{t} 1}+\left[\left(2 f_{11} l_{\mathrm{o}}^{2}\right) / v\right] \dot{\psi}_{\omega 1}+\left[\left(2 f_{11} a \lambda\right) / r_{\mathrm{o}}\right] y_{\omega 1} \\
& I_{\omega z} \ddot{\psi}_{\omega 2}=2 b_{1}^{2} K_{\mathrm{px}} \psi_{\omega 2}-2 b_{1}^{2} K_{\mathrm{px}} \psi_{\mathrm{t} 1}+\left[\left(2 f_{11} l_{\mathrm{o}}^{2}\right) / v\right] \dot{\psi}_{\omega 2}+\left[\left(2 f_{11} a \lambda\right) / r_{\mathrm{o}}\right] y_{\omega 2} \\
& I_{\omega z} \ddot{\psi}_{\omega 3}=2 b_{1}^{2} K_{\mathrm{px}} \psi_{\omega 3}-2 b_{1}^{2} K_{\mathrm{px}} \psi_{\mathrm{t} 2}+\left[\left(2 f_{11} l_{\mathrm{o}}^{2}\right) / v\right] \dot{\psi}_{\omega 3}+\left[\left(2 f_{11} a \lambda\right) / r_{\mathrm{o}}\right] y_{\omega 3} \\
& I_{\omega z} \ddot{\psi}_{\omega 4}=2 b_{1}^{2} K_{\mathrm{px}} \psi_{\omega 4}-2 b_{1}^{2} K_{\mathrm{px}} \psi_{\mathrm{t} 2}+\left[\left(2 f_{11} l_{\mathrm{o}}^{2}\right) / v\right] \dot{\psi}_{\omega 4}+\left[\left(2 f_{11} a \lambda\right) / r_{\mathrm{o}}\right] y_{\omega 4}
\end{aligned}
$$

The symbols used in above equations are defined in Table A.1 in the appendix.

\subsection{Calculation of the critical speed of a high-speed train}

Based on above equations, the governing equation can be written as

$[\mathbf{M}]\{\ddot{\mathbf{q}}\}+[\mathbf{C}]\{\dot{\mathbf{q}}\}+[\mathbf{K}]\{\mathbf{q}\}=\{\mathbf{0}\}$ 
Where

$\{\mathbf{q}\}=\left[\begin{array}{lllllllllllllll}y_{\mathrm{c}} & \theta_{\mathrm{c}} & \psi_{\mathrm{c}} & y_{\omega 1} & \psi_{\omega 1} & y_{\omega 2} & \psi_{\omega 2} & y_{\omega 3} & \psi_{\omega 3} & y_{\omega 4} & \psi_{\omega 4} & y_{\mathrm{t} 1} & \psi_{\mathrm{t} 1} & y_{\mathrm{t} 2} & \psi_{\mathrm{t} 2}\end{array}\right]^{\mathrm{T}}$

is the generalized coordinates vector.

Defining the state vector

$\{y\}=\left\{\begin{array}{c}q \\ \dot{q}\end{array}\right\}$

Then the above governing equation can be written as

$\{\dot{y}\}=[\mathbf{A}]\{y\}$

Where

$$
[\mathbf{A}]=\left[\begin{array}{cc}
{\left[\mathbf{A}_{1}\right]} & {\left[\mathbf{A}_{2}\right.} \\
{\left[\mathbf{A}_{3}\right]} & {[\mathbf{0}]}
\end{array}\right]
$$

Which is known as the dynamic matrix. Where

$$
\begin{aligned}
& {\left[\mathbf{A}_{1}\right]=\left[[\mathbf{M}]^{-1}[\mathbf{C}]\right]} \\
& {\left[\mathbf{A}_{2}\right]=\left[[\mathbf{M}]^{-1}[\mathbf{K}]\right]} \\
& {\left[\mathbf{A}_{3}\right]=[\mathbf{I}]}
\end{aligned}
$$

The mass matrix $[\mathbf{M}]$, damping matrix $[\mathbf{C}]$ and stiffness matrix $[\mathbf{K}]$ are obtained by the transformation matrix method [13]. Then the eigenvalue of the dynamic matrix $\lambda$ is calculated using MATLAB.

$$
\lambda_{2 j-1,2 j}=\alpha_{j} \pm i \beta_{j} \quad(i=\sqrt{-1}, j=1-n)
$$

Where $n$ denotes the number of degree-of-freedom

$\alpha_{j}$ and $\beta_{j}$ are, respectively, the real and imaginary part of the eigenvalue of system dynamic matrix.

The damping ratio can be expressed as follows: 


$$
\zeta_{j}=-\alpha_{j} / \sqrt{\alpha_{j}^{2}+\beta_{j}^{2}}
$$

Table 1. Motions of the 15-degree-of-freedom high-speed train model

\begin{tabular}{c|c|c|c}
\hline \multirow{2}{*}{ Component } & \multicolumn{3}{|c}{ Motion } \\
\cline { 2 - 4 } & Lateral & Roll & Yaw \\
\hline Front truck leading wheelset & $\mathrm{y}_{\omega 1}$ & -- & $\psi_{\omega 1}$ \\
\hline Front truck trailing wheelset & $\mathrm{y}_{\omega 2}$ & -- & $\psi_{\omega 2}$ \\
\hline Rear truck leading wheelset & $\mathrm{y}_{\omega 3}$ & -- & $\psi_{\omega 3}$ \\
\hline Rear truck trailing wheelset & $\mathrm{y}_{\omega 4}$ & -- & $\psi_{\omega 4}$ \\
\hline Front truck frame & $\mathrm{y}_{\mathrm{t} 1}$ & -- & $\psi_{\mathrm{t} 1}$ \\
\hline Rear truck frame & $\mathrm{y}_{\mathrm{t} 2}$ & -- & $\psi_{\mathrm{t} 2}$ \\
\hline Carboy & $\mathrm{y}_{\mathrm{c}}$ & $\theta_{\mathrm{c}}$ & $\psi_{\mathrm{c}}$ \\
\hline
\end{tabular}
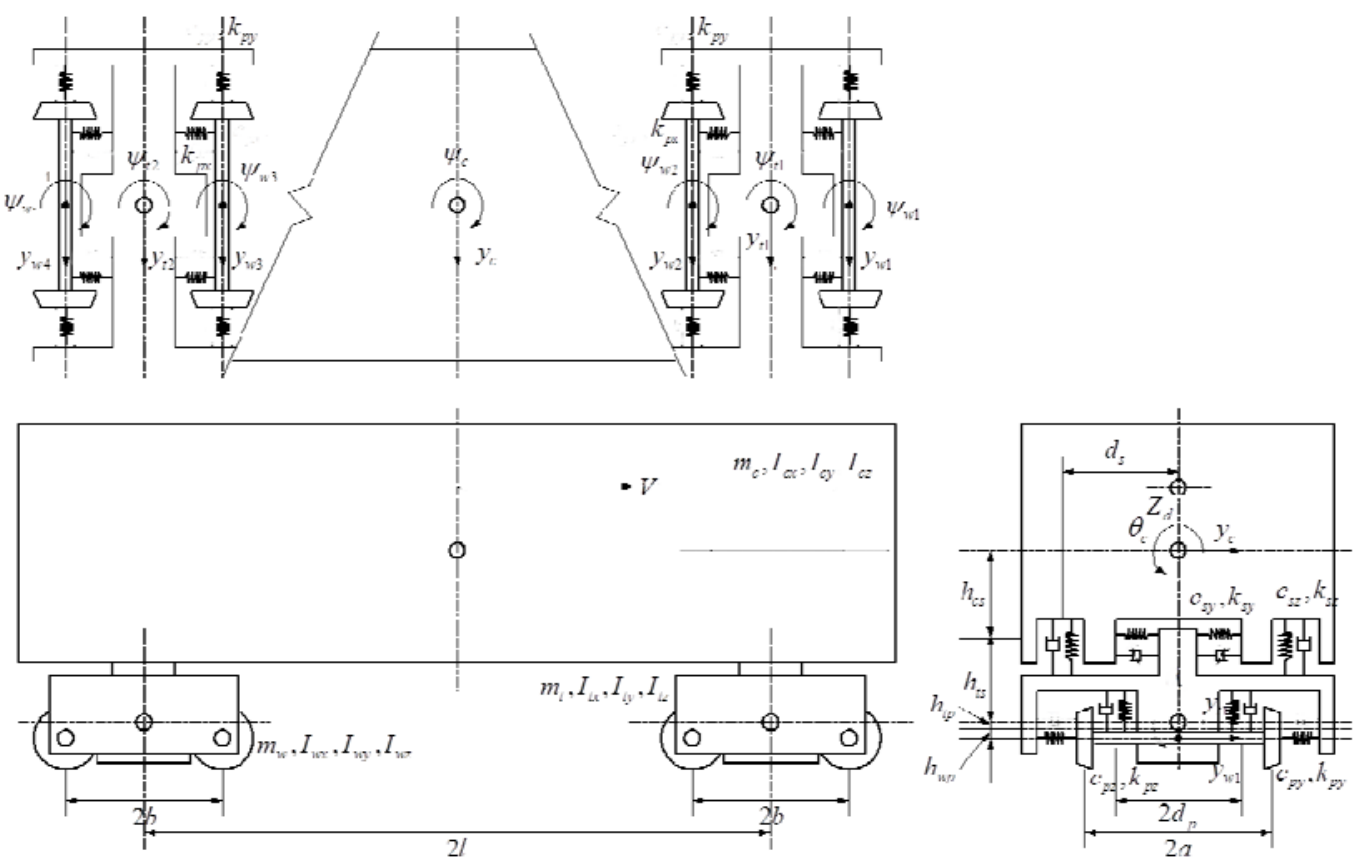

Fig.1. Analytical model of a high-speed train

Following the above equations, the damping ratio of the 15-DOF can be worked out. As the train speed is included in the train dynamic matrix, any variation in the speed of the train induces a change in the damping ratio. Thus, as the train speed increases, 
the damping ratios may reduce and cross the zero line. The train speed at the point where the damping ratio crosses the zero line is the critical speed. Consequentially, the critical speeds of each DOF can be worked out.

\subsection{Theoretical analysis of the effect of an MRF damper on train critical speed}

The motion of the vehicle with MRF dampers is given by

$[\mathbf{M}]\{\ddot{x}(t)\}+[\mathbf{C}(v)]\{\dot{x}(t)\}+[\mathbf{K}(v)]\{x(t)\}+[\mathbf{F}(A, x, \ddot{x})]=[\mathbf{0}]$

Where $\{\mathrm{x}(\mathrm{t})\}$ is the general displacement column, $[\mathbf{M}],[\mathbf{C}]$ and $[\mathbf{K}]$ are the mass, damping and stiffness matrices, respectively. They are speed dependent and can be derived by multi-body dynamics analysis. $\mathrm{F}(\mathrm{A}, \mathrm{x}, \ddot{x})$ is the introduced force by MRF damper which is related to current $\mathrm{A}$ and displacement.

If the vehicle system has a passive damper, the eigenvalue equation is derived as

$$
[\mathbf{M}] \lambda^{2}+\left[[\mathbf{C}(v)]+\left[\mathbf{C}_{\mathbf{p}}\right]\right] \lambda+[\mathbf{K}(v)]=[\mathbf{0}]
$$

Where $\left[\mathbf{C}_{p}\right]$ is the damping of the passive damper. From Eq. (2.22), the eigenvalue of the vehicle/structure system is speed dependent. At certain speeds, the real part of the eigenvalue may become positive, which induces the vehicle/structure instability. This speed is called the critical speed. When the vibration becomes unstable, the amplitude of the motion grows exponentially in time and theoretically achieves infinity theoretically in a linear system. The intrinsic instability of the vehicle/structure system is independent of the type of excitation. Therefore, once the whole system has been designed, a passive damper cannot improve the stability property in the system because the eigenvalue is determined when the parameters of the system are fixed. Similarly, if the vehicle system has an MRF damper, the eigenvalue equation becomes

$$
[\mathbf{M}] \lambda^{2}+\left[[\mathbf{C}(v)]+\left[\mathbf{C}_{\mathrm{MR}}\right]\right] \lambda+\left[[\mathbf{K}(v)]+\left[\mathbf{K}_{\mathrm{MR}}\right]\right]=[\mathbf{0}]
$$

Where $\left[\mathbf{C}_{\mathrm{MR}}\right]$ and $\left[\mathbf{K}_{\mathrm{MR}}\right]$ are the MRF dampers induced variable damping and variable stiffness, respectively, and these two parameters definitely have an effect on the critical speed. With a proper designed MR damper and a suitable control algorithm, 
the critical speed is able to be above the operation speed of railway vehicles. Thus the vibration of railway vehicles close to the critical speed can be well controlled by an MRF damper.

\section{The effect of train speed on the damping ratio of each train DOF}

The dynamic matrix of a train contains variable parameters and train speed. Thus, as the velocity of a train increases, the train damping ratio varies. The damping ratio of each DOF determines the train's critical speed. In order to investigate the different influence of each DOF on critical speeds, the damping ratios of the train's 15-DOF with different train speeds are calculated. The damping ratio of the front truck wheelsets, rear truck wheelsets, truck frames and car body with respect to train speed are shown from Fig.2 to Fig.5 respectively.

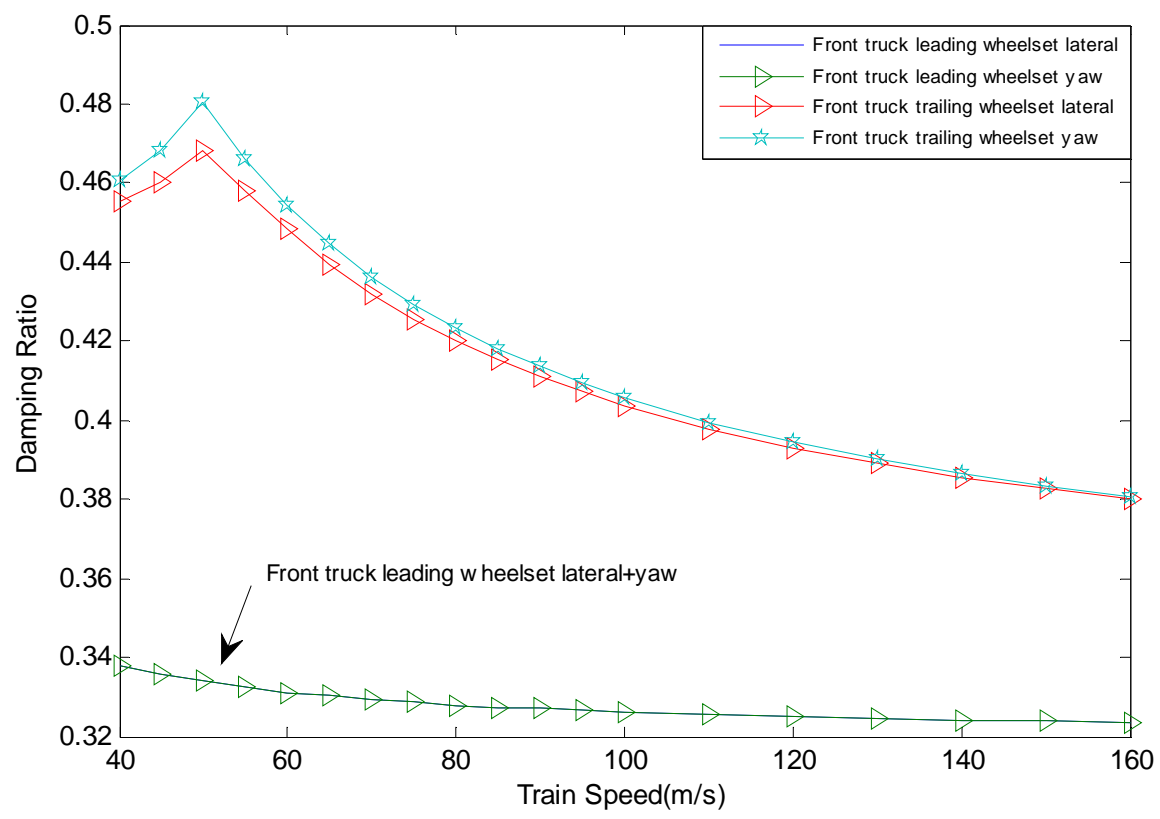

Fig.2. Damping ratios of the front truck wheelsets response modes

The influence of train speed on the damping ratios of the front truck wheelsets is presented in Fig.2. The figure shows that the various damping ratios of the front truck trailing wheelsets lateral and yaw motion progress similarly with train speed that the damping ratios increase slightly until peak at 0.47 and 0.48 respectively then decrease continually but do not cross the zero line. The figure also indicates that the damping 
ratio of the truck leading wheelsets lateral and yaw motion is not sensitive to the train speed. An increase in train speed from $40 \mathrm{~m} / \mathrm{s}$ to $160 \mathrm{~m} / \mathrm{s}$ only decreases the damping ratio of the truck leading wheelset by $3 \%$.

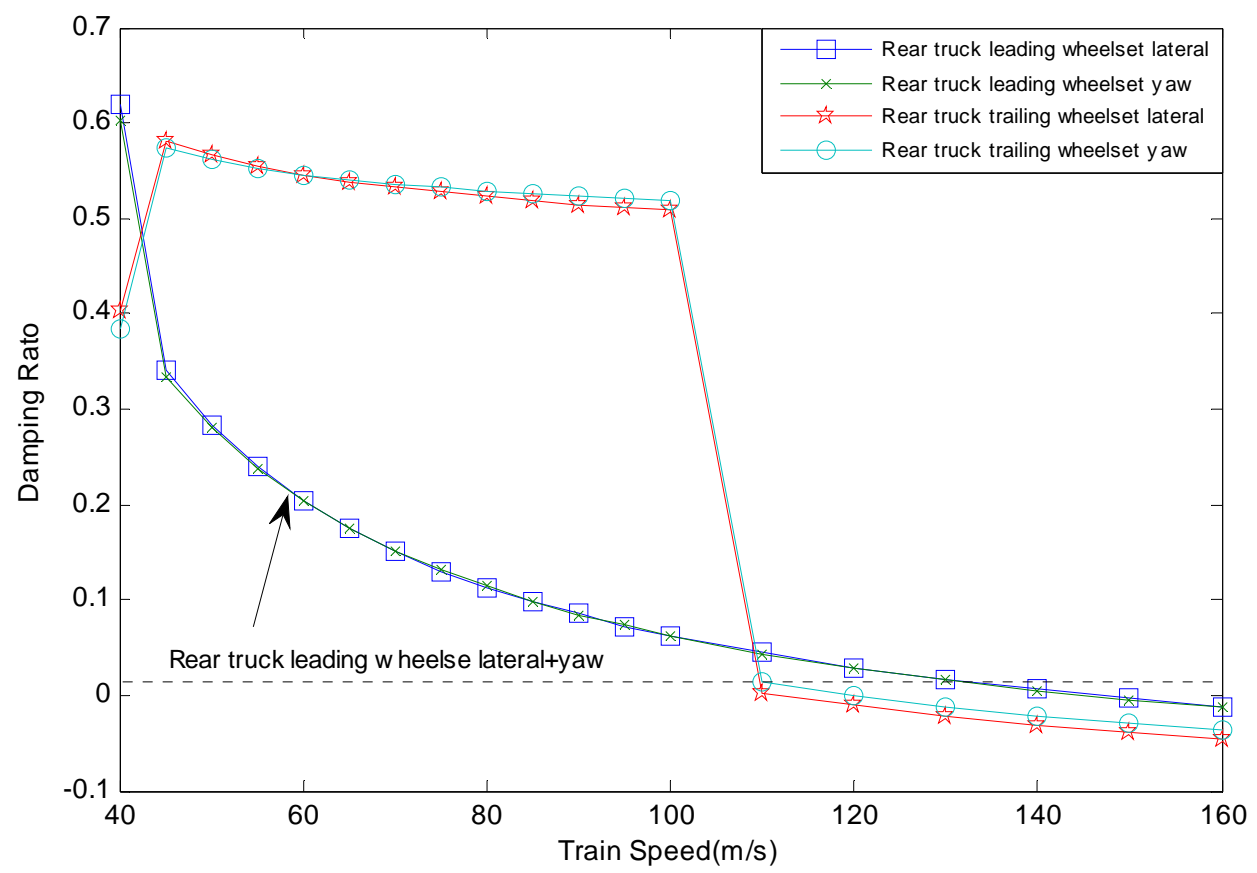

Fig.3. Damping ratios of the rear truck wheelsets response modes

Fig. 3 shows the influence of train speed on the damping ratios of the rear truck wheelsets. The figure indicates that the damping ratio of the rear truck leading wheelset reduces significantly and crosses the zero line at $133 \mathrm{~m} / \mathrm{s}$, which is the critical speed of the rear truck leading wheelset. The damping ratio of the rear truck trailing wheelset is basically unchanged at first but decreases sharply at a speed of $100 \mathrm{~m} / \mathrm{s}$, and then crosses the zero line at $110 \mathrm{~m} / \mathrm{s}$ which is the critical speed of the rear truck leading wheelset. 


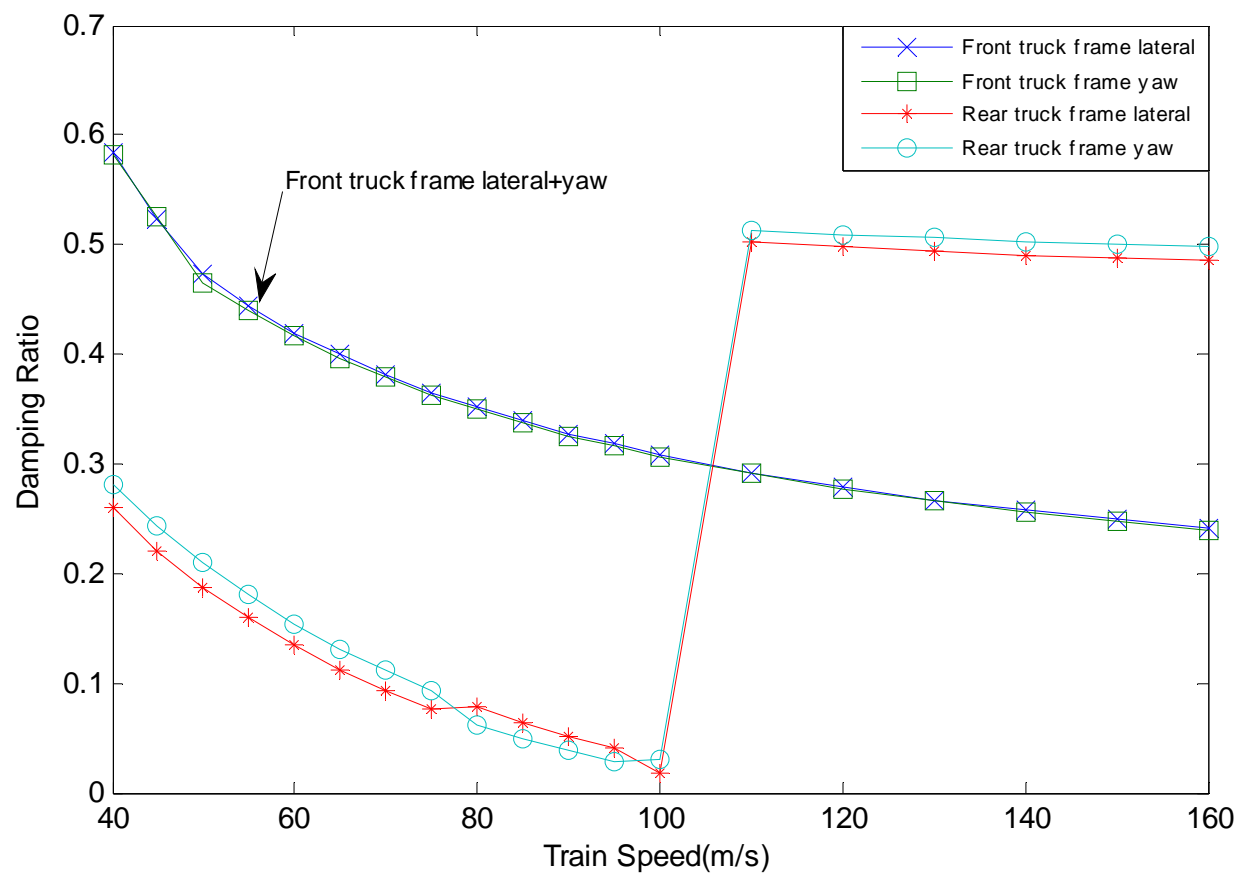

Fig.4. Damping ratios of truck frames response modes

The effect of variations in the train speed on the damping ratios of truck frames is illustrated in Fig.4. The damping ratio of the front truck frame is inversely proportional to the train speed and does not cross the zero line. The damping ratio of the rear truck frame declines until the train speed reaches $100 \mathrm{~m} / \mathrm{s}$, then the damping ratio increases dramatically and levels off at 0.5 . 


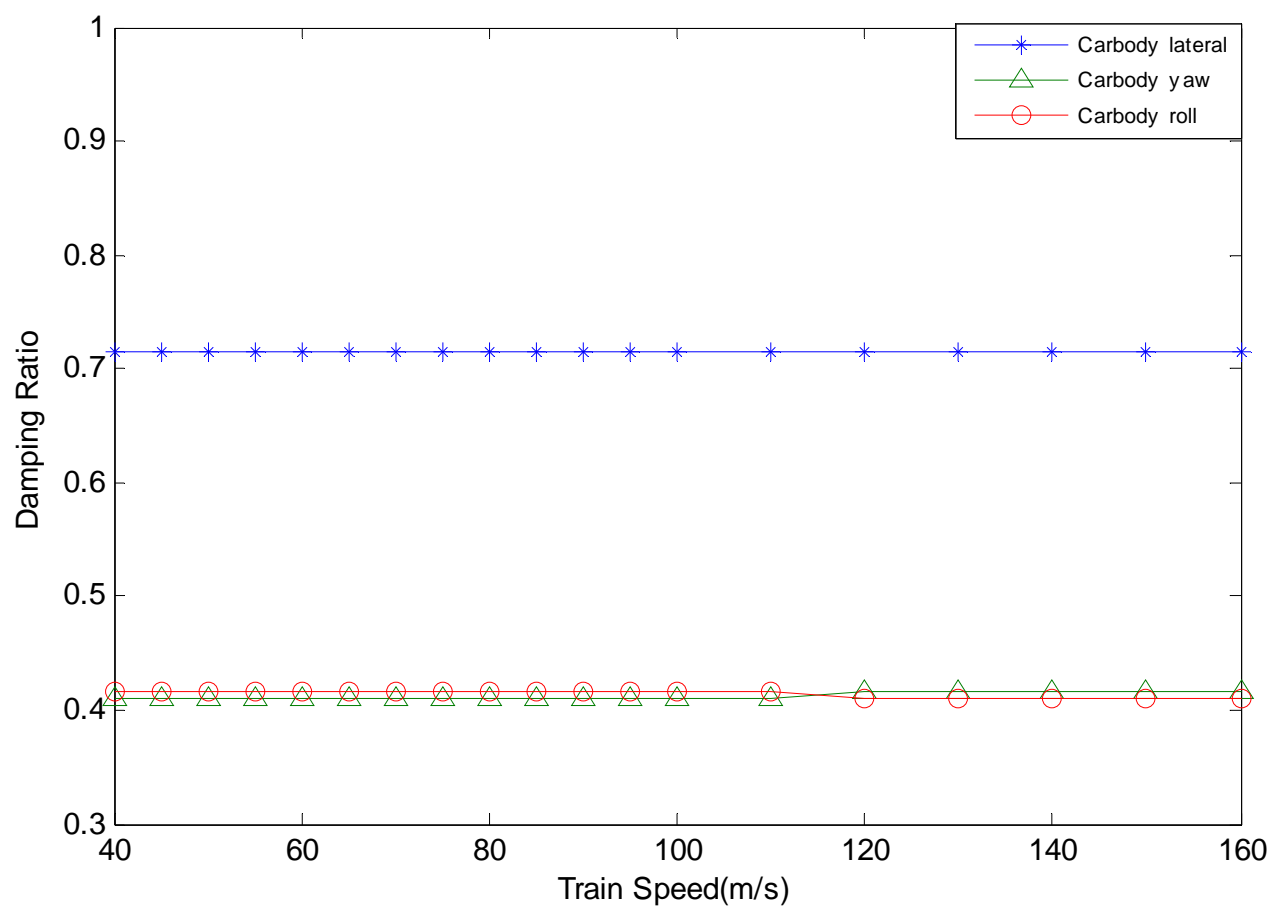

Fig.5. Damping ratios of car body response modes

As shown in Fig.5, the damping ratio of the car body is basically not influenced by the train speed. That the damping ratio remains above the zero line means the car body is stable even though the train reaches a high level of speed. Based on the above figures, the damping ratios of each DOF responding to the train speed vary from each other. From the damping ratio analysis, the rear truck wheelset and rear truck frame are more unstable than other components of the train.

\section{The influence of suspension parameters on critical speeds of each train DOF}

When the damping ratio reduces and crosses the zero line, the train reaches its critical speed. The change of suspension parameter induces a variation of the crossing point which determines the train's critical speed. Therefore, the critical speed of a high-speed train is directly related to the suspension parameters and it is crucial to study the effect of suspension parameters on the critical speeds of each train DOF.

As the train speed increases, some certain train DOFs become unstable, which means the train reaches its critical speed in these DOFs. In such cases, the whole train reaches its critical speed as well. Thus, the critical speed of the whole train can be 
obtained by taking the minimum critical speed of each train DOF at each point. Critical speeds which exceed $200 \mathrm{~m} / \mathrm{s}$ are out of discussion in this paper because the current operating speed is much lower than $200 \mathrm{~m} / \mathrm{s}$. The following figures show the effect of the train suspension parameters on the critical speeds of several train DOFs. For the sake of simplicity in describing the following figures, $\mathrm{C}$ with different subscripts represents the critical speeds of different train DOFs. C with two subscript letters represents the critical speeds of the truck frame. The first letter ('f 'or ' $r$ ') is used to represent the front and rear truck frames, respectively. The secondary letter (' 1 ' or ' $y$ ') represents the lateral motion and yaw motion. C with three subscript letters represents the critical speeds of the truck frame wheelsets. The first letter (' $\mathrm{f}$ ' or ' $\mathrm{r}$ ') is used to identify the front truck frame and rear truck frame, respectively. The secondary letter (' $t$ ' or ' $\mathrm{l}$ ') is used to identify the trailing and leading wheelsets. The third letter ('l' or ' $y$ ') identifies the lateral and yaw motion. The different meanings of each symbol are also shown in table A.2.

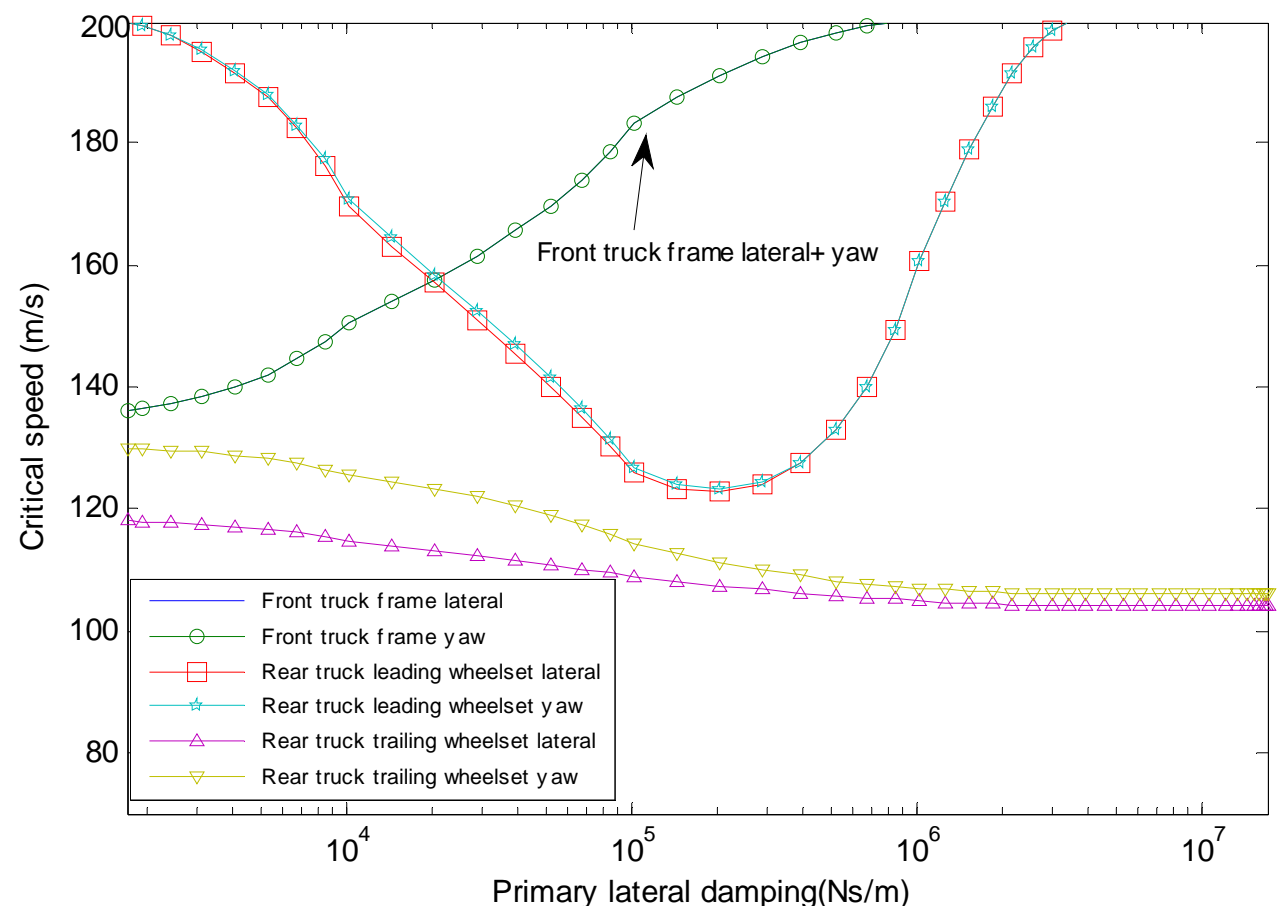

Fig.6 Critical speed versus primary lateral damping

As plotted in Fig.6, the effect of primary lateral damping on the critical speeds of each train DOF is demonstrated. The increase in primary lateral damping continually 
improves the $\mathrm{C}_{\mathrm{fl}}$ and $\mathrm{C}_{\mathrm{fy}}$. Dissimilarly, $\mathrm{C}_{\mathrm{rtl}}$ and $\mathrm{C}_{\mathrm{rty}}$ decline slightly, although $\mathrm{C}_{\mathrm{rll}}$ and $\mathrm{C}_{\mathrm{rly}}$ had the same trend of declining first and bottoming out at $120 \mathrm{~m} / \mathrm{s}$ then showing an upward trend.

The critical speed of the whole high-speed train with respect to primary lateral damping is the same as the effect of primary lateral damping on $\mathrm{C}_{\mathrm{rtt}}$, because the value of $\mathrm{C}_{\mathrm{rtl}}$ is the minimum at each point. In other words the whole train critical speed is dominated by lateral motion in the rear truck trailing wheelset when the primary lateral damping is changed. Based on the curve, this increase in the primary lateral damping reduces the critical speed by $8.3 \%$.

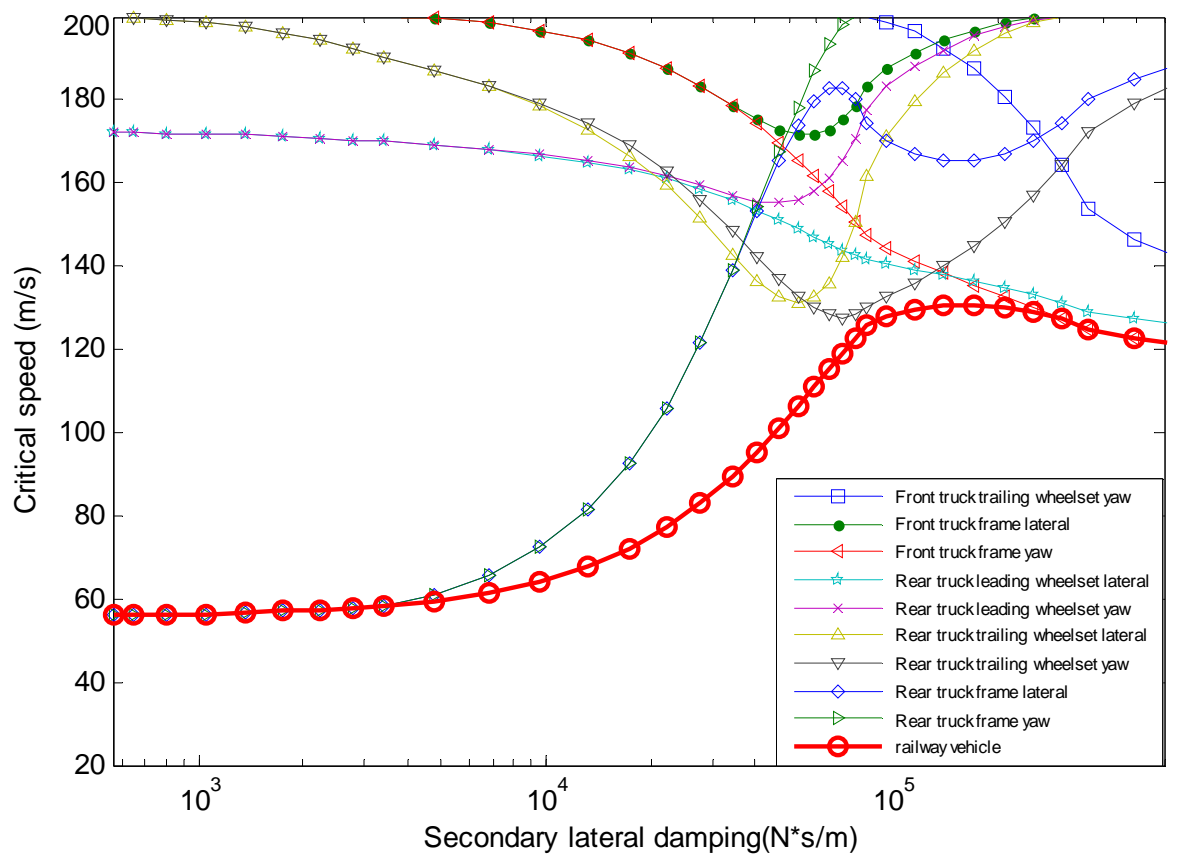

Fig.7 Critical speed versus secondary lateral damping

Fig.7 shows the effect of secondary lateral damping on the critical speeds of each train DOF. As the secondary lateral damping increases $\mathrm{C}_{\mathrm{rl}}$ and $\mathrm{C}_{\mathrm{ry}}$ show a basic upward trend, whereas $\mathrm{C}_{\mathrm{fty}}, \mathrm{C}_{\mathrm{fy}}$ and $\mathrm{C}_{\mathrm{rll}}$ reduce constantly. $\mathrm{C}_{\mathrm{fl}}, \mathrm{C}_{\mathrm{rly}}, \mathrm{C}_{\mathrm{rtl}}$ and $\mathrm{C}_{\mathrm{rty}}$ share the same trend of reducing before $8 \times 10^{4} \mathrm{Ns} / \mathrm{m}$ then increasing after that point as the primary lateral damping keeps on increasing. Based on the figure, with the variation of secondary lateral damping, the whole train critical speed is restricted by the lateral 
and yaw motion of rear truck frame before $5 \times 10^{4} \mathrm{~N} \mathrm{~s} / \mathrm{m}$. Then the rear truck trailing wheelset yaw and front truck frame yaw motions dominate the whole train's critical speed in turn. The critical speed of the whole high speed train climbs to $130 \mathrm{~m} / \mathrm{s}$ and then levels off as the secondary lateral damping increases.

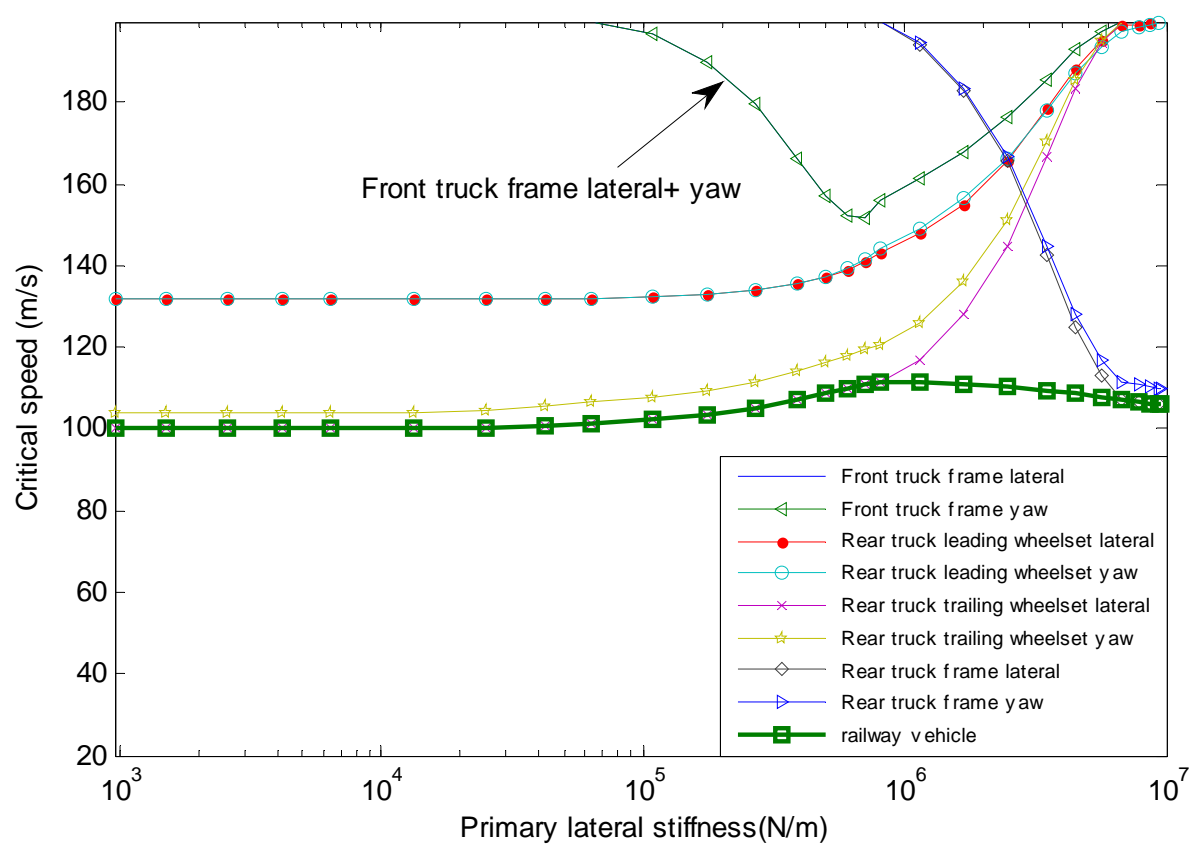

Fig.8 Critical speed versus primary lateral stiffness

Fig.8 indicates the effect of primary lateral stiffness on the critical speeds of each train DOF. The variation of primary lateral stiffness from $1000 \mathrm{~N} / \mathrm{m}$ to $1 \times 10^{7} \mathrm{~N} / \mathrm{m}$ increases $\mathrm{C}_{\mathrm{rtl}}, \mathrm{C}_{\mathrm{rll}}, \mathrm{C}_{\mathrm{rty}}$ and $\mathrm{C}_{\mathrm{rly}}$ by $43 \%, 50 \%$, and $49 \%$ respectively, whereas $\mathrm{C}_{\mathrm{rl}}$ and $\mathrm{C}_{\mathrm{ry}}$ show a downward trend, $C_{\mathrm{fl}}$ and $\mathrm{C}_{\mathrm{fy}}$ reduce before $7 \times 10^{5} \mathrm{~N} / \mathrm{m}$ and then rise to $200 \mathrm{~m} / \mathrm{s}$ after that.

As shown in Fig. 8 the whole train critical speed is limited by the lateral motion in the rear truck trailing wheelset and rear truck frame when the primary lateral stiffness is changed. Then the critical speed of the high-speed train increases to $110 \mathrm{~m} / \mathrm{s}$ before showing a downward trend as the primary lateral stiffness increases. 


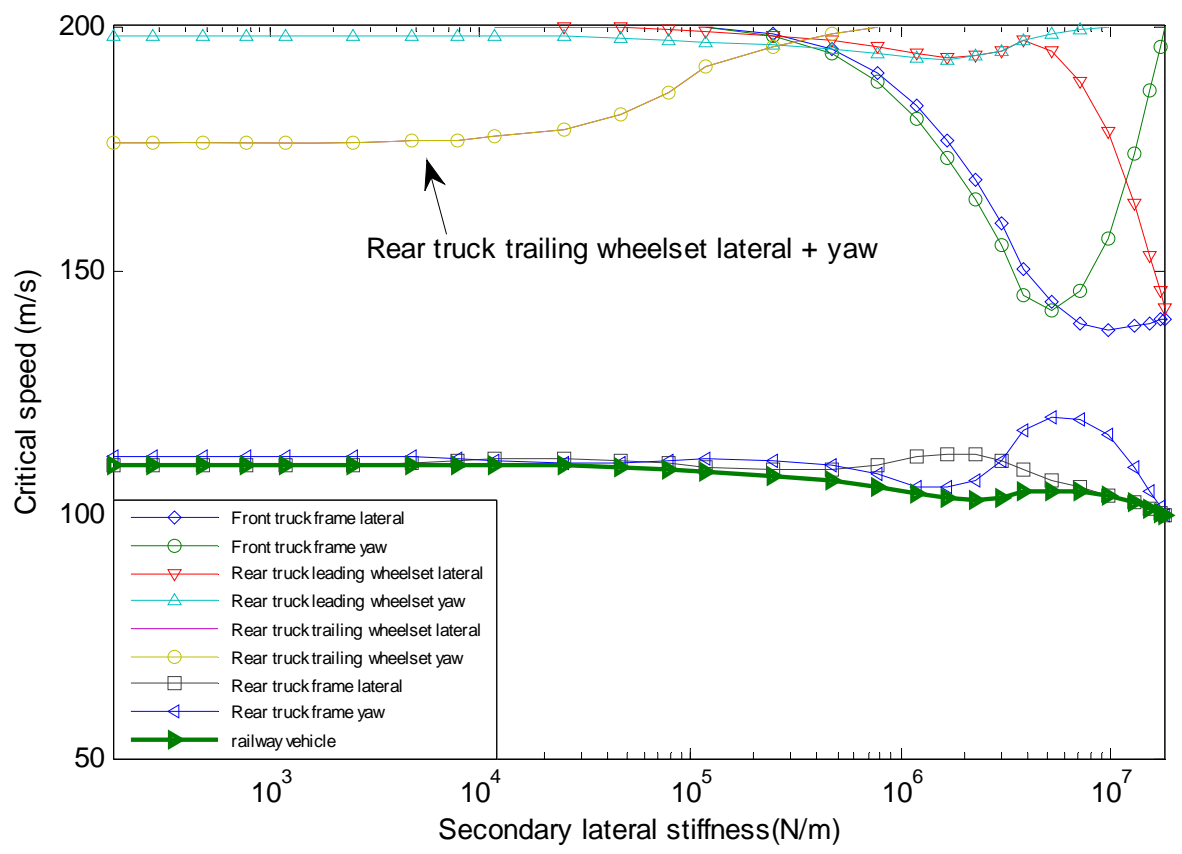

Fig.9 Critical speed versus secondary lateral stiffness

As shown in Fig.9, $\mathrm{C}_{\text {rly }}$ and $\mathrm{C}_{\mathrm{fy}}$ decrease at first and then show an upward trend, but $\mathrm{C}_{\mathrm{ry}}$ and $\mathrm{C}_{\mathrm{rl}}$ remain basically the same. The increase in the secondary lateral stiffness reduces the $C_{\mathrm{rll}}$ and $\mathrm{C}_{\mathrm{rl}}$ while the increase in secondary lateral stiffness improves $\mathrm{C}_{\mathrm{rtl}}$ and $\mathrm{C}_{\text {rty. }}$.

Based on an analysis of the figure, the lateral and yaw motions of the rear truck frame confine the whole train's critical speed. This figure also shows that the critical speed of a high-speed train is inversely proportional to its secondary lateral stiffness. This increase in the secondary lateral stiffness from $1000 \mathrm{~N} / \mathrm{m}$ to $1 \times 10^{7} \mathrm{~N} / \mathrm{m}$ reduces the critical speed by $4 \%$.

The above four figures provide the effect of a suspension parameter on the critical speeds of each train DOF, which offers a guideline to train design. The change trends of the critical speed with respect to different suspension parameters vary from each other. These four figures also show that the critical speed of the whole train is dominated by the critical speeds of the rear truck frame and rear truck wheelset. Thus, the conclusion that the critical speeds of rear truck frame and rear truck wheelset 
restricts the whole train critical speed can be drawn. As a result, more attention should be paid to the rear truck frame and rear truck wheelset when we intend to improve the train critical speed.

\section{The sensitivity analysis of the critical speed of a high-speed train}

The effect of suspension parameters on the critical speeds of each train DOF is plotted in the former section where the influence of various suspension parameters on the whole train critical speed is discussed. The sensitivity of the whole train critical speed with respect to the suspension parameters is calculated to investigate which parameter impacts the train critical speed most.

The sensitivity analysis is focused on the relationship between the designed variable available to the engineer and the system response and has been adopted in many research areas [31-33]. Based on the sensitivity analysis, the designer can carry out a systematic trade-off analysis [32], and resigning a system can be processed [31]. J Jang and Han devise a way to conduct dynamic sensitivity analysis for studying state sensitive information with respect to changes in the design variables [34]. Park applies sensitivity analysis into the pantograph dynamic analysis for a high-speed rail vehicle [35]. The sensitivity analysis for the effect of bogie stiffness and damping on the critical speeds contributes a lot to enhance train critical speed. It can predict which stiffness and damper will affect the critical speed most and which range of the bogie parameter will have a severe impact on the critical speed. Thus, the results of the sensitivity analysis will help guide the design of bogie parameters. However, the sensitivity of bogie stiffness and damping on the critical speeds is very rare in the existing research, to the best of the author's knowledge.

In this section the sensitivity of the train critical speed with respect to the suspension parameters is measured. A measurement of the sensitivity of the $i$ th suspension parameter $x_{i}$ is given as,

$$
S=\frac{\Delta C_{\mathrm{w}}}{C_{\mathrm{w}}} / \frac{\Delta x_{i}}{x_{i}}
$$


Where $\mathrm{S}$ is the sensitivity of the critical speed, $\Delta C_{\mathrm{w}}$ is the variation of train critical speed induced by the change of suspension parameters, $C_{\mathrm{w}}$ is the changed critical speed, $\Delta x_{i}$ is the variation of the $i$ th suspension parameter, and $x_{i}$ is the changed $i$ th suspension parameter.

The result of the train critical speed with respect to lateral and vertical damping is shown in Fig.10. Based on this figure the train critical speed is insensitive to the variation of primary and secondary vertical damping.

This increase in primary lateral damping results in a reduction of the train critical speed. Compared to the above three curves, the critical speed is more sensitive to secondary lateral damping. As the secondary lateral damping increases, the train critical speed jumps to $136 \mathrm{~m} / \mathrm{s}$ and then declines gently to $112 \mathrm{~m} / \mathrm{s}$.

Fig.11 presents the results of the train critical speed with respect to the lateral and longitudinal stiffness. As shown in Fig.11, the train critical speed is less sensitive to primary and secondary lateral stiffness compared to primary longitudinal stiffness. Similarly, the train speed is not sensitive to any variation of primary longitudinal stiffness from $1000 \mathrm{~N} / \mathrm{m}$ to $2 \times 10^{5} \mathrm{~N} / \mathrm{m}$, but when the primary longitudinal increases from $2 \times 10^{5} \mathrm{~N} / \mathrm{m}$ to $2 \times 10^{6} \mathrm{~N} / \mathrm{m}$, the train critical speed is improved by $300 \%$.

Fig. 12 indicates the sensitivity of the critical speed with respect to vertical and lateral damping. It is observed that the train critical speed is affected by secondary lateral damping $\left(\mathrm{C}_{\mathrm{sy}}\right)$, secondary vertical damping $\left(\mathrm{C}_{\mathrm{sz}}\right)$, primary lateral damping $\left(\mathrm{C}_{\mathrm{py}}\right)$ and primary vertical damping $\left(\mathrm{C}_{\mathrm{pz}}\right)$, but $\mathrm{C}_{\mathrm{sz}}, \mathrm{C}_{\mathrm{py}}, \mathrm{C}_{\mathrm{pz}}$ is not as sensitive as $\mathrm{C}_{\mathrm{sy}}$. The figure also shows that the sensitivity ascends and peaks at 0.45 , which is around $8 \times 10^{5} \mathrm{Nm} / \mathrm{s}$, and then it shows a downward trend and reduces to 0 , around $5 \times 10^{7} \mathrm{Nm} / \mathrm{s}$, as the $\mathrm{C}_{\mathrm{sy}}$ increases.

Fig.13 shows the sensitivity of the critical speed with respect to secondary lateral stiffness $\left(\mathrm{K}_{\mathrm{sy}}\right)$, the primary lateral stiffness $\left(\mathrm{K}_{\mathrm{py}}\right)$, and the primary longitudinal stiffness $\left(\mathrm{K}_{\mathrm{px}}\right)$. But the sensitivity of critical speeds corresponding to $\mathrm{K}_{\mathrm{sy}}$ and $\mathrm{K}_{\mathrm{py}}$ 
remains at a lower level compared with that corresponding to $\mathrm{K}_{\mathrm{px}}$. This is explained that as $\mathrm{K}_{\mathrm{px}}$ increases, the sensitivity remains unchanged at first, and then jumps to 1.05 around $1 \times 10^{6} \mathrm{~N} / \mathrm{m}$ and descends to 0 when the stiffness increases to $1 \times 10^{7} \mathrm{~N} / \mathrm{m}$.

The average sensitivity of different bogie stiffness and damping parameters is illustrated in Fig.14 where $\mathrm{K}_{\mathrm{px}}$ and $\mathrm{C}_{\mathrm{sy}}$ are the two parameters that most affect the train critical speed. Here the influence of $\mathrm{K}_{\mathrm{sy}}, \mathrm{K}_{\mathrm{py}}$ and $\mathrm{C}_{\mathrm{py}}$ on train critical speed is reduced in turn and the $\mathrm{C}_{\mathrm{pz}}$ and $\mathrm{C}_{\mathrm{sz}}$ have almost no effect on the critical speed.

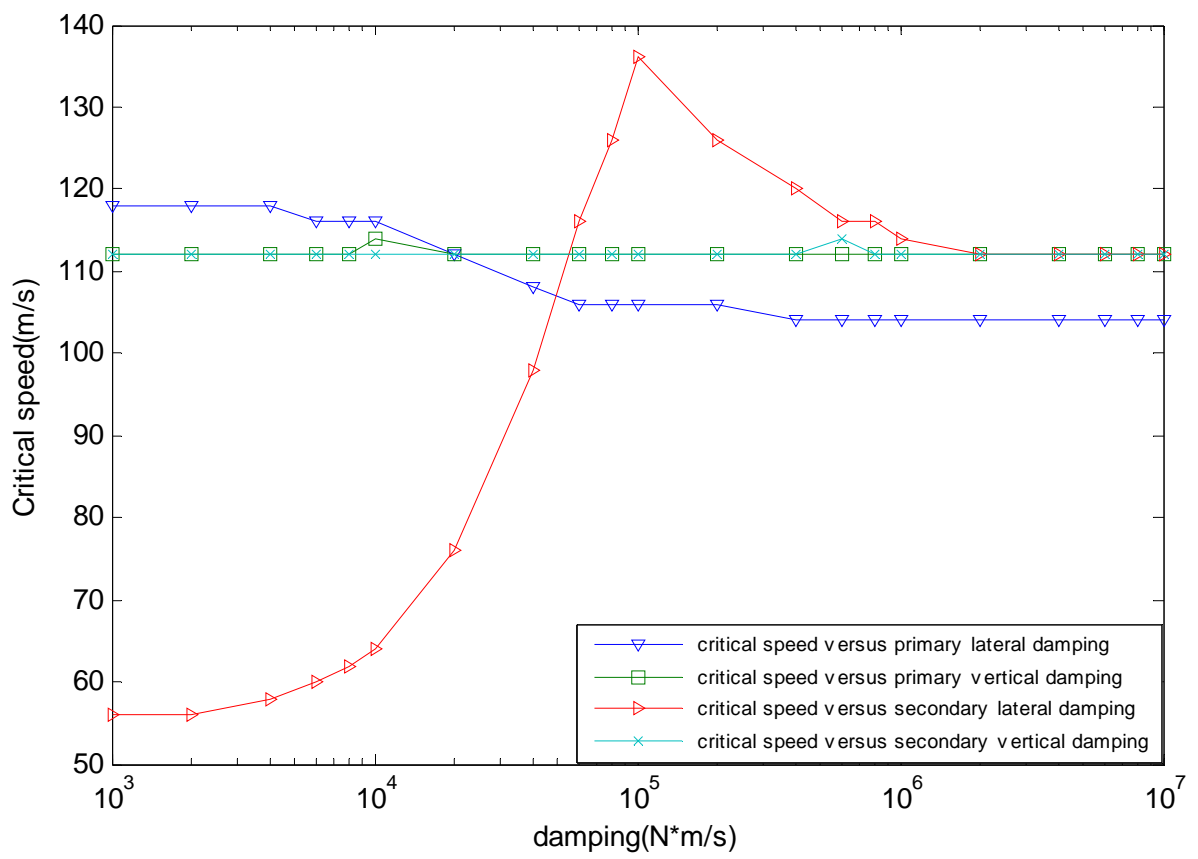

Fig.10 Train critical speed versus various bogie damping 


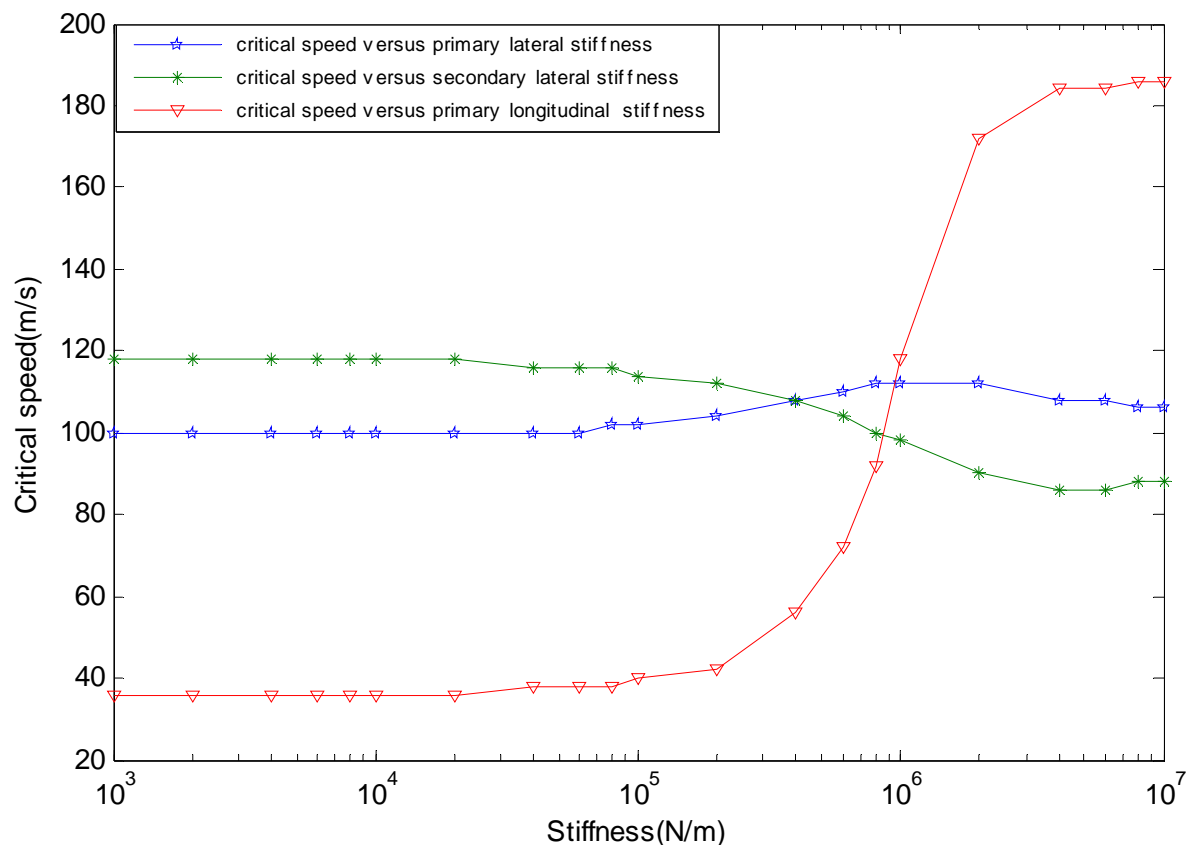

Fig.11 Train critical speed versus various bogie stiffness

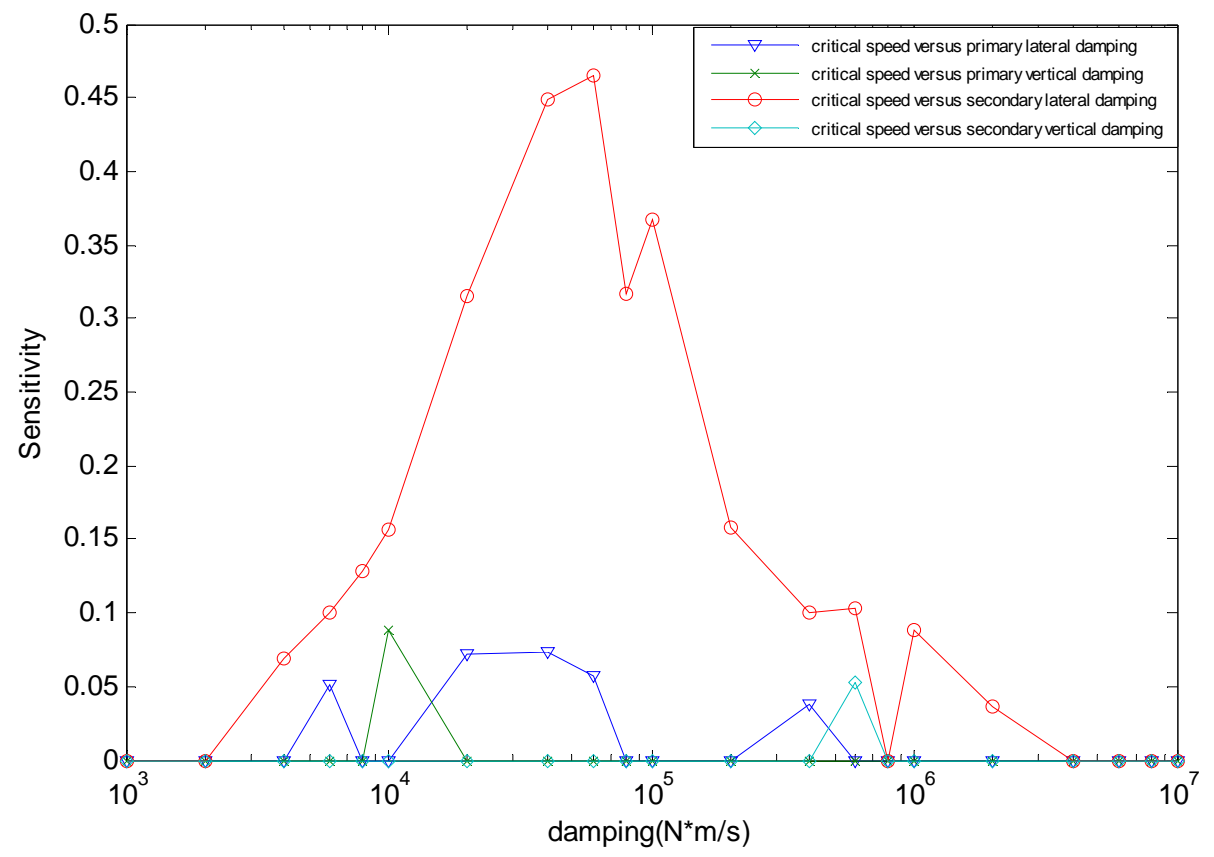

Fig.12 Sensitivity of train critical speed versus various bogie damping 


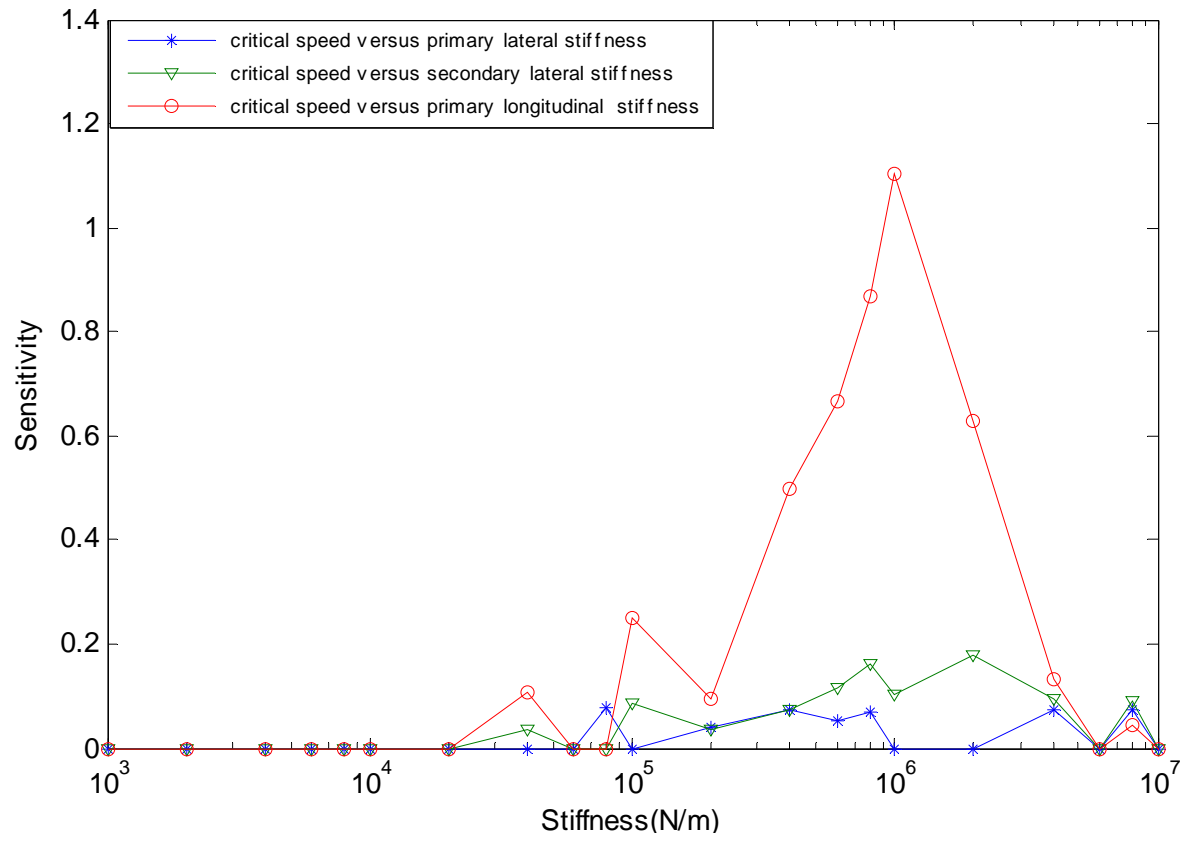

Fig.13 Sensitivity of train critical speed versus various bogie stiffness

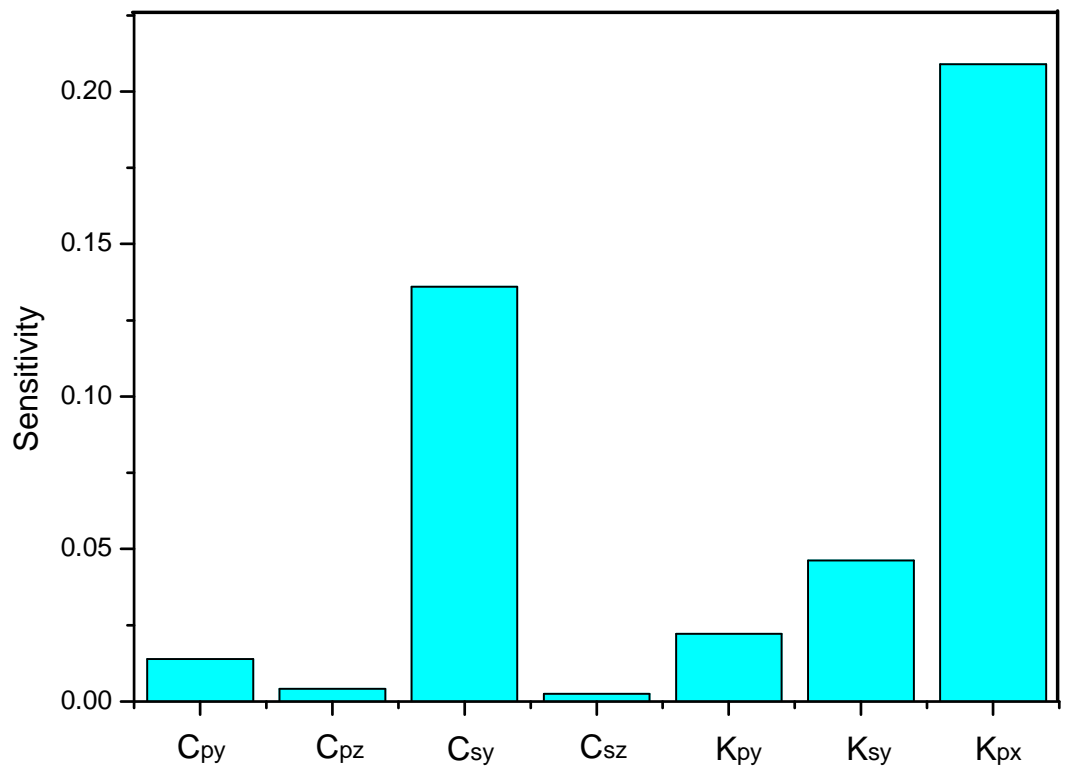

Fig.14 The average sensitivity of train critical speed with respect to different bogie stiffness and damping parameters

It can be seen from the above figures that the secondary lateral damping and primary longitudinal stiffness are the two most sensitive parameters impacting the critical 
speed compared to the other bogie parameters of the train. Thus, more attention should be paid to these two parameters when we aim to increase the train critical speed. It can also be concluded that the most sensitive range of secondary lateral damping is from $1 \times 10^{4} \mathrm{Ns} / \mathrm{m}$ to $5 \times 10^{5} \mathrm{Ns} / \mathrm{m}$ while the most sensitive range of the primary longitudinal stiffness is from $1 \times 10^{5} \mathrm{~N} / \mathrm{m}$ to $3 \times 10^{6} \mathrm{~N} / \mathrm{m}$.

\section{The simulation of a high-speed train with an MR damper}

Based on the above analysis, secondary lateral damping has the most influence on train critical speed, and as a result, the secondary damper is replaced by an MR damper in this simulation. In this paragraph a high-speed train model imbedded with four MR dampers is established by ADMAS software and the control strategy is built in MATLAB/SIMULINK. In this way the simulation of a high-speed train with MRF dampers can be realized and a random irregular track is applied to investigate how the MR dampers effect on the train critical speed.

\subsection{Modeling of a high-speed train}

In order to establish the dynamic model of the high-speed train, software called ADAMS/RAIL is used in this research because it contains detailed models of suspension components such as the wheelset, bogie frame, train body, and so on.

The model established in this paper is a two-axle railway vehicle containing a front truck and rear truck frame, as shown in Fig.15. The truck frames, as shown in Fig.16, built in this paper contain primary and secondary suspension. The primary suspension consists of four primary vertical dampers and four primary vertical springs while the secondary suspension consists of two secondary vertical dampers, two secondary vertical springs, and secondary lateral dampers. 


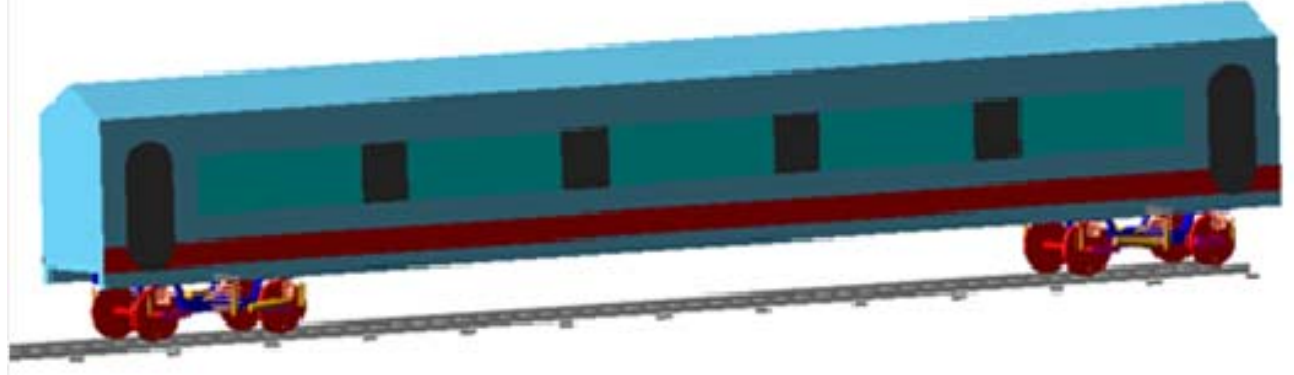

Fig.15 Dynamic model of a high-speed train

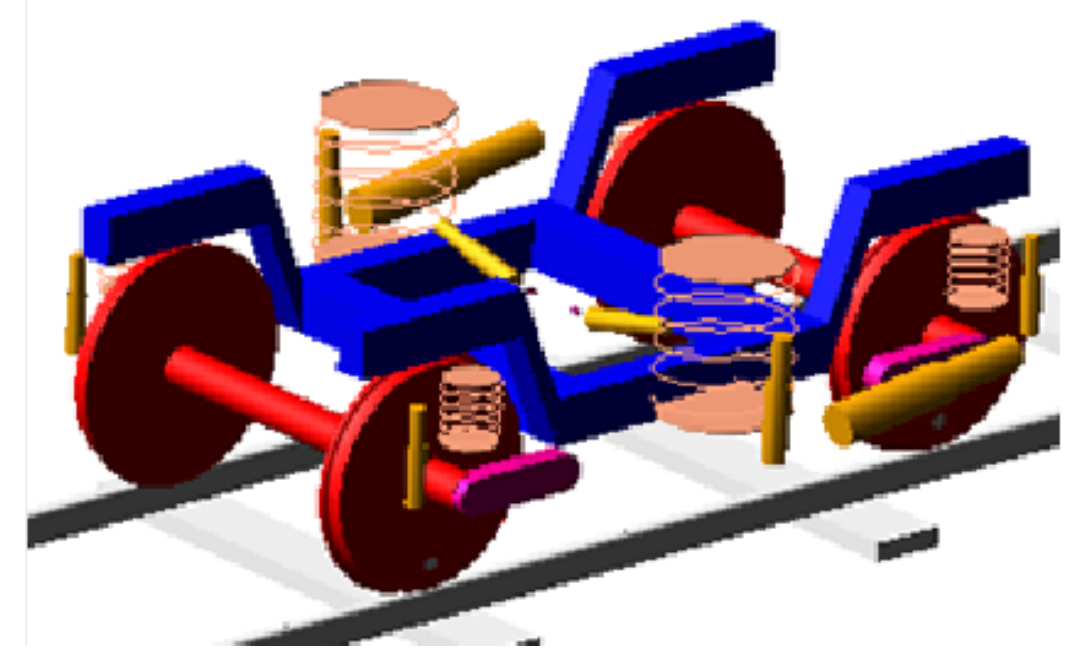

Fig.16 Dynamic model of suspension of high-speed train

\subsection{Modeling of MR damper}

Different kinds of models have been used to describe the behavior of MR dampers, such as the Bingham model, the Bouc-Wen model, the viscoelastic-plastic model, and so on. The dynamic phenomenological model adopted in this paper to describe the dynamic performance of the MR damper is based on the model built by Yang [36]. This model is based on the Bouce-Wen model, including the MR fluid stiction phenomenon and the shear thinning effects illustrated in Fig.17. The damper force $F_{O}$ is determined by following equations.

$$
\begin{aligned}
& \dot{z}=-\gamma\left|\dot{x}_{\mathrm{o}}\right||z|^{n-1} z-\beta_{\mathrm{o}} \dot{x}_{\mathrm{o}}|z|^{n}+A_{\mathrm{o}} \dot{x}_{\mathrm{o}} \\
& F_{\mathrm{o}}-f_{\mathrm{o}}=\alpha_{\mathrm{o}} z+k_{\mathrm{o}} x_{\mathrm{o}}+c_{\mathrm{o}}\left(\dot{x}_{\mathrm{o}}\right) \dot{x}_{\mathrm{o}}+m_{\mathrm{o}} \ddot{x}_{\mathrm{o}} \\
& c_{\mathrm{o}}\left(\dot{x}_{\mathrm{o}}\right)=a_{1} e^{-\left(a_{2}\left|\dot{x}_{\mathrm{o}}\right|\right)^{p}}
\end{aligned}
$$


The damping force is determined by Eq. (6.2), and the functional parameter $\alpha_{0}$ is governed by the input current. $k_{\mathrm{o}}, f_{\mathrm{o}}$ and $c_{o}\left(\dot{x}_{o}\right)$ are the accumulator, friction force, and post-yield plastic damping coefficient respectively. $m_{\mathrm{o}}$ is adopted to emulate the MR fluid stiction and inertia effect, and Eq. (6.1) represents the Bouce-Wen model. The evolutionary variable $z$ is determined by $\gamma, \beta_{0}, A_{o}$ and $n$. The force-displacement and force-velocity relationship of the MR damper used in this simulation is shown in Fig. 18

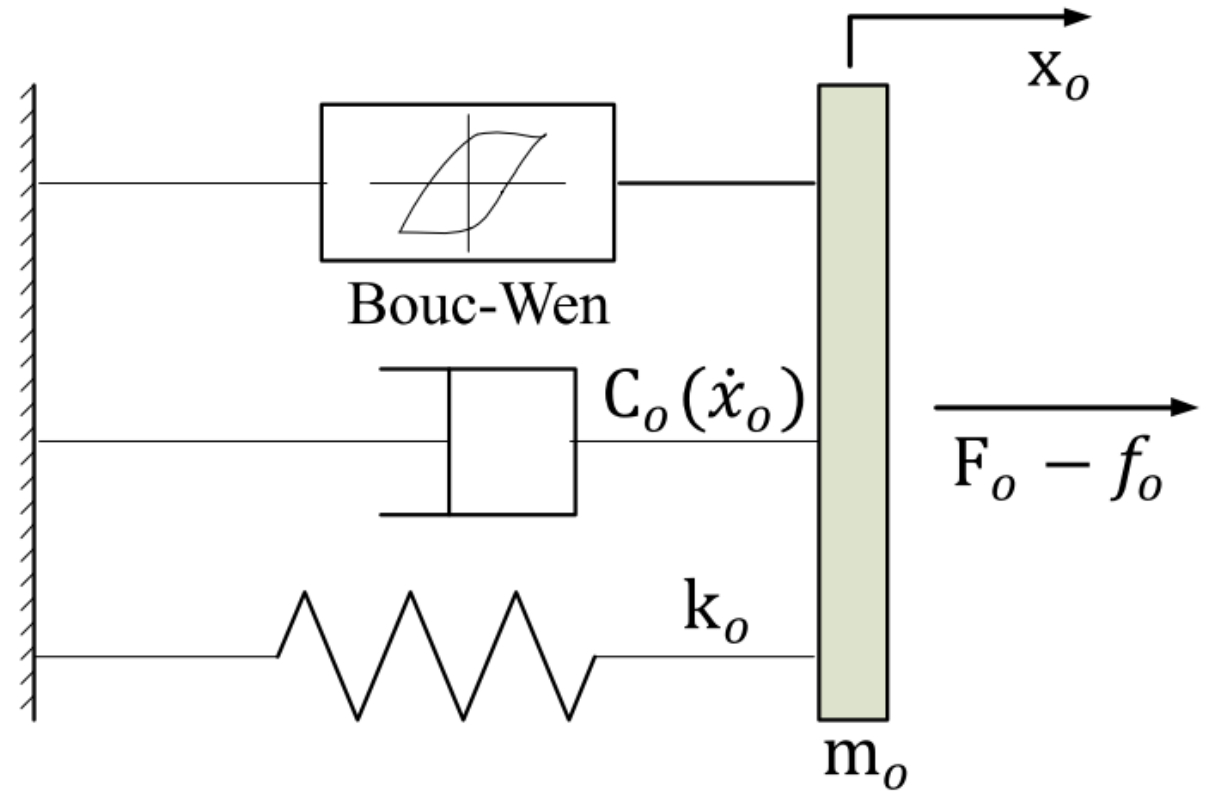

Fig.17. MR damper mathematical model 


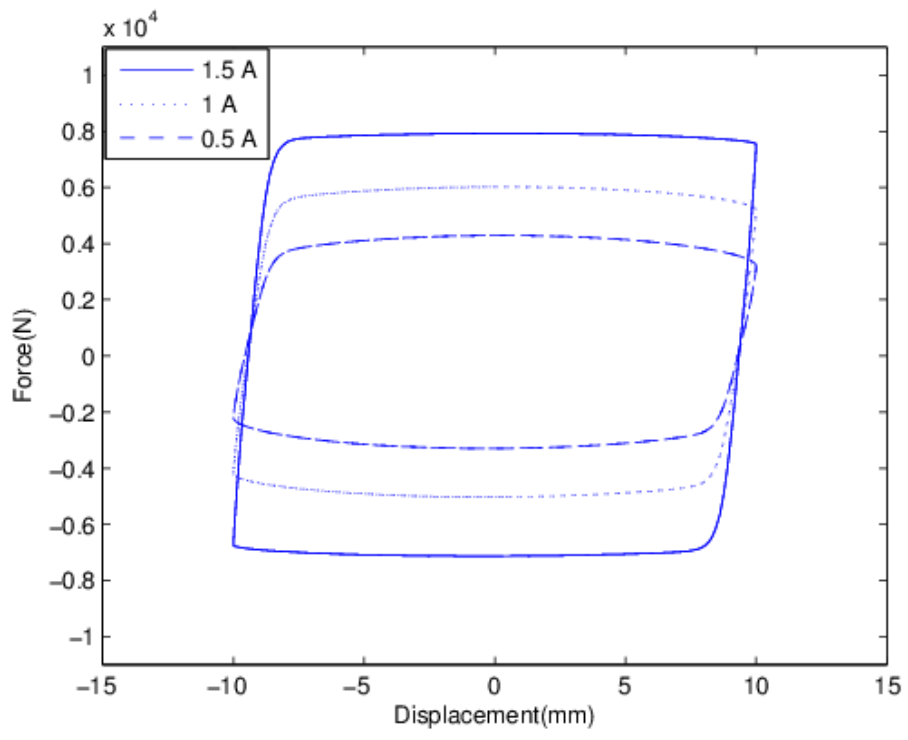

$\mathrm{a}$

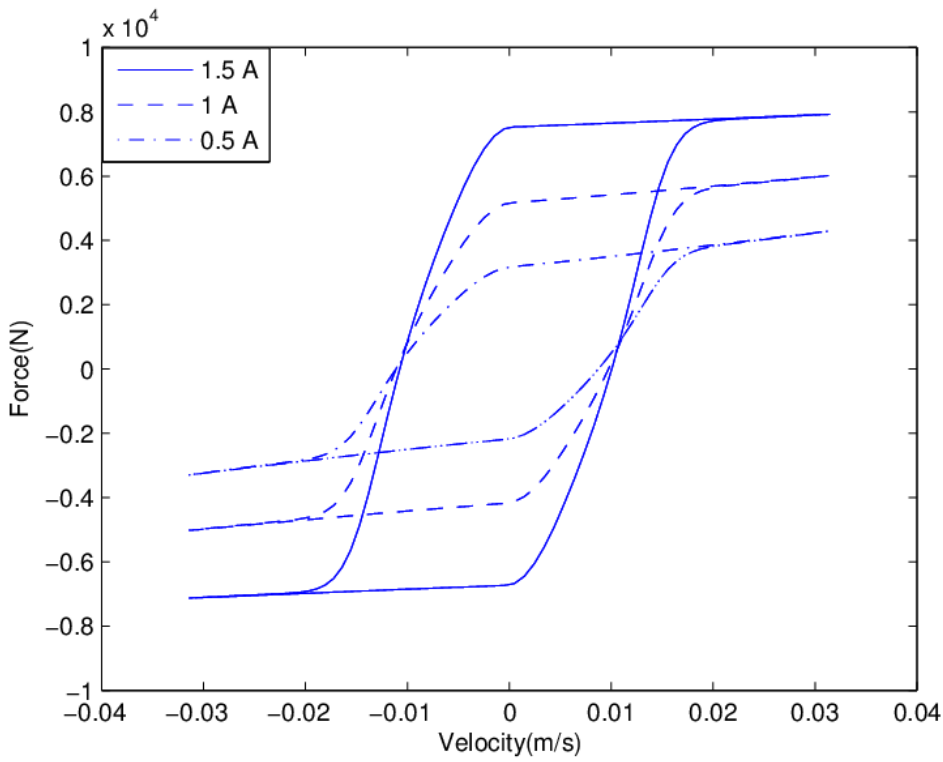

b

Fig.18. Force-displacement (a) and force-velocity (b) relationship of MR damper

\subsection{The control strategy}

The main purpose of the controller is to determine the desired damping force in order to enhance the train critical speed. The control strategy adopted in this article is the skyhook-groundhook hybrid control. Details of the skyhook-goundhook control strategy are as follows: 


$$
\begin{aligned}
& \mathrm{F}_{\text {sky }}= \begin{cases}-\alpha c_{\max }\left(\dot{x}_{2}-\dot{x}_{1}\right) & \dot{x}_{2}\left(\dot{x}_{2}-\dot{x}_{1}\right) \geq 0 \\
-\alpha c_{\min }\left(\dot{x}_{2}-\dot{x}_{1}\right) & \dot{x}_{2}\left(\dot{x}_{2}-\dot{x}_{1}\right)<0\end{cases} \\
& \mathrm{F}_{\text {gnd }}= \begin{cases}-(1-\alpha) c_{\max }\left(\dot{x}_{2}-\dot{x}_{1}\right) & \dot{x}_{1}\left(\dot{x}_{2}-\dot{x}_{1}\right) \geq 0 \\
-(1-\alpha) c_{\min }\left(\dot{x}_{2}-\dot{x}_{1}\right) & \dot{x}_{1}\left(\dot{x}_{2}-\dot{x}_{1}\right)<0\end{cases} \\
& \mathrm{F}=\mathrm{F}_{\text {sky }}+\mathrm{F}_{\text {gnd }}
\end{aligned}
$$

where $\quad \mathrm{F}_{s k y}$ is the force generated by skyhook control strategy. $\mathrm{F}_{\text {gnd }}$ is the force generated by groundhook strategy. $\alpha$ is the scalar denoting the force proportion generated by skyhook control. The $c_{\max }, c_{\min }$ are the maximum and minimum damping coefficient the damper can provide. $\dot{x}_{1}, \dot{x}_{2}$ are the absolute lateral velocities of bogie frame and car body.

The skyhook control is used to control the vibration of car body while the goundhook control is used to suppress the wheelset's vibration. The two control strategy is connected by parameter $\alpha$. As the main purpose of this paper is to improve train's critical speed, the parameter $\alpha$ is set to be 0.2 .

\subsection{Assembly of semi-active high-speed train and simulation}

The dynamic model of the high-speed train is established in ADAMS, while the MR damper model and control strategy are built in MATLAB.. The composition of the semi-active train model is shown in Fig.19. 


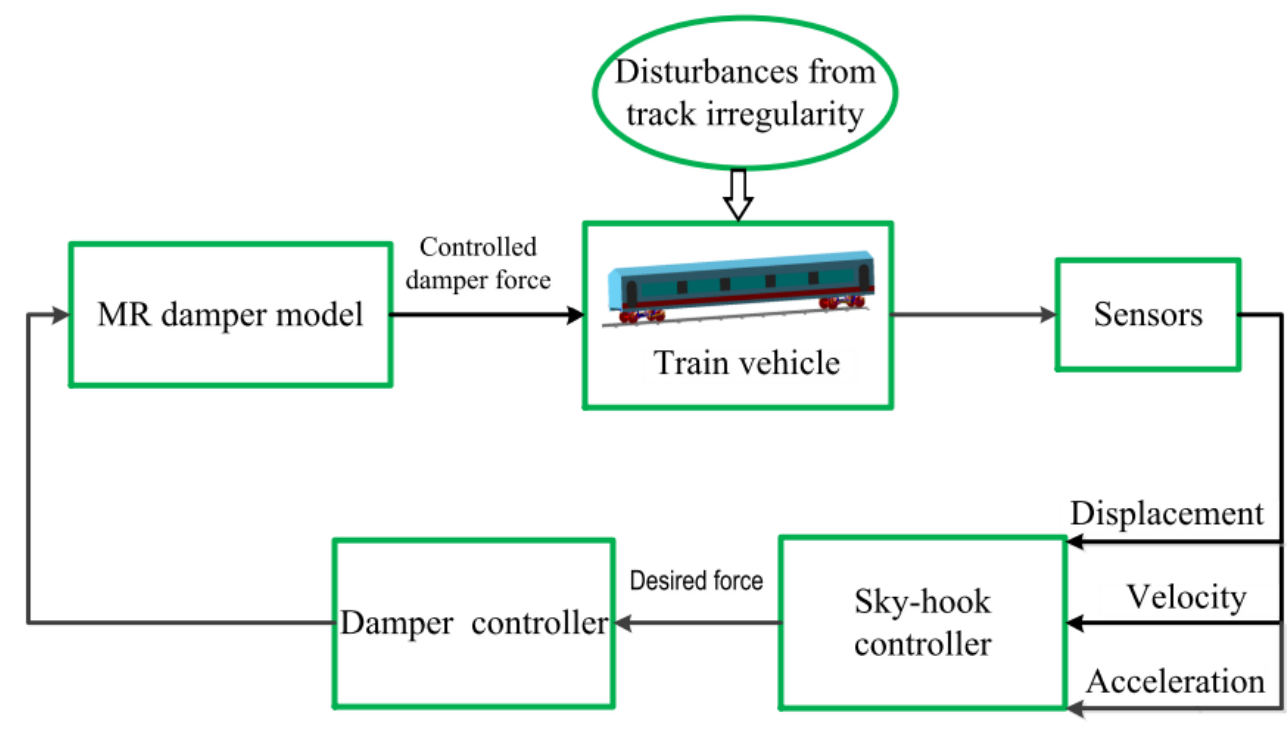

Fig.19 Composition of semi-active train model

\subsection{Simulation and results}

The combination of ADAMS and Matlab is adopted in this simulation where the high-speed train with the MR damper will be simulated on a random irregular track. Three different suspension systems are simulated in this section. They are semi-active, passive-on, and passive-off. The definitions of the three suspension systems are as follows: semi-active: suspension system with controlled MR dampers mounted on the secondary suspension system; passive-on: suspension system with uncontrolled MR dampers (constant applied current 1 A by providing relatively high damping) mounted on the secondary suspension system; passive-off: suspension system with uncontrolled MR dampers (constant applied current 0 A by providing relatively low damping) mounted on the secondary suspension system. The simulation results of the train installed with passive-on damper, passive-off damper and semi-active damper are shown in Fig.20, Fig.21 and Fig.22 respectively.

Displacement of the wheelset is measured to characterize the train critical speed, it will remain at a low level before the train reaches its critical speed but jump to a high level after the train reaches the critical speed, which means the critical speed of train can be worked out by analyzing the displacement of the wheelsets. 


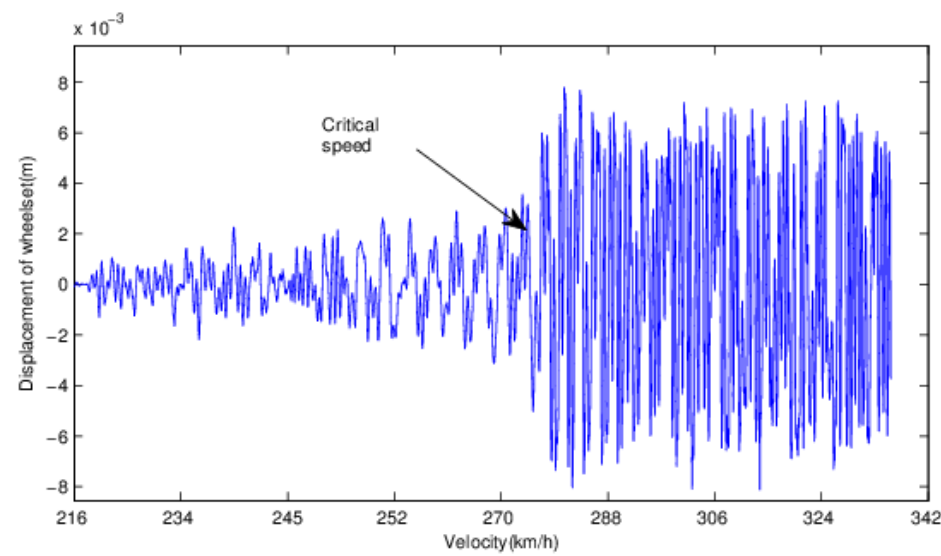

Fig.20 The displacement of wheelset vs the speed of the high-speed train with a passive-off damper

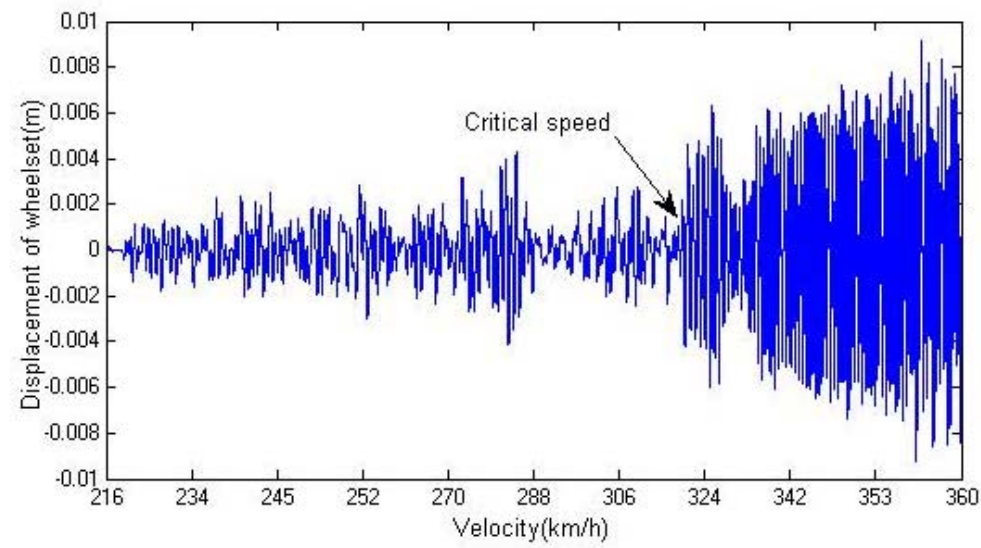

Fig.21 The displacement of wheelset vs the speed of the high-speed train with a passive-on damper

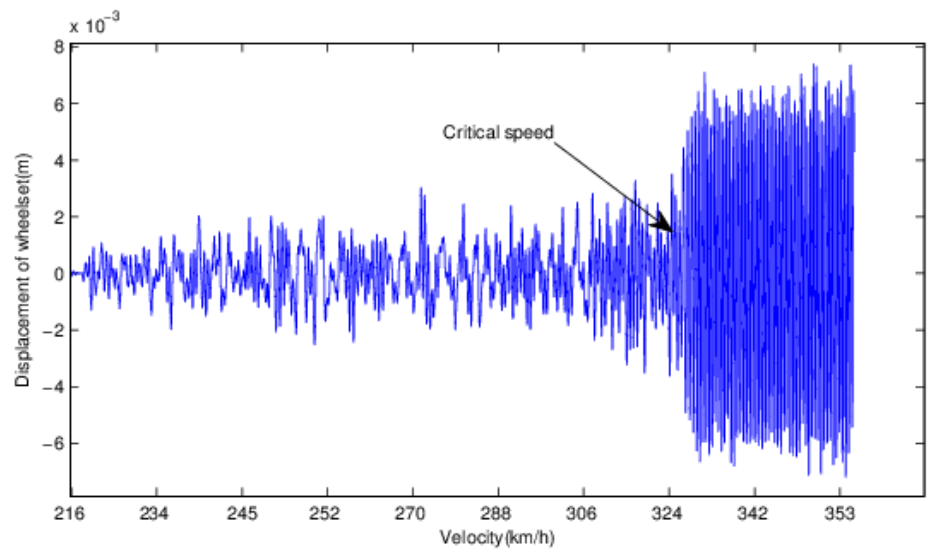

Fig.22 The displacement of the wheelset vs the speed of a high-speed train with an semi-acitve MR damper 
Fig.20 shows the displacement of the wheelset of a high-speed train with a passive-off secondary lateral damper. The figure indicates that the displacement remains at a low level before the train speed reaches $275 \mathrm{~km} / \mathrm{s}$ and then it suddenly jumps to a high level, denoting that $275 \mathrm{~km} / \mathrm{h}$ is the critical speed of the high-speed train. Fig.21 demonstrates the critical speed of the train mounted with passive-on MR damper is $319 \mathrm{~km} / \mathrm{h}$. Similarly, Fig.22 indicates that the critical speed of train with a semi-active MR damper is $328 \mathrm{~km} / \mathrm{s}$. From Fig.20 and Fig.21, it can be found out that the increase of damping coefficient of secondary dampers leads to the increase of train critical speed. Also, the three Figures demonstrate the critical speed of the train with a controllable MR damper is higher than the train with passive-on or passive-off damper

In this section a high-speed train with an MRF damper is established by ADMAS and MATLAB. The Bouce-Wen model is adopted to model the MR damper and the skyhook-groundhook hybrid control strategy is used to control the damping force. The simulation result illustrates that the MRF damper significantly improves the train critical speed.

\section{The experimental research on the effect of the MRF damper on the stability of a high-speed train}

The simulation of the train with an MRF damper verifies that it can enhance the train critical speed. In this section, the secondary dampers of a high-speed train are replaced by the MRF dampers and then the train is tested in a roller rig test platform

to verify the simulation result and investigate the effect of MRF damper on train critical speed.

\subsection{Experimental facilities}

The high speed train Harmony is used to do the experimental research in this part. It is installed onto the roller rig experimental platform, as shown in Fig.23, and it contains the front and rear truck frames. Each truck frame built in this paper incorporates primary and secondary suspension. The roller rig which is available in the state key 
laboratory for railway is used as an experimental platform to test the high-speed train installed with MRF dampers. The roller rig can be viewed as a track simulator which simulates an endless track by using rollers. It can test a high-speed train operating at different speeds without field tests. The roller rig has six rollers which can move in vertical and lateral directions independently under servo control. Of these six rollers, four have the ability of gauge variation between 1000 and $1676 \mathrm{~mm}$ and two rollers can run at different rotational speeds which allow the roller rig to simulate six types of irregularities, including cross level, gauge, curve, and so on.

The MRF dampers are installed between the bogie and car body, as shown in Fig.24. A current driver, MRF damper controller, and accelerometers are also included to run the experiment.

\subsection{Setup of experiment system}

The high-speed train where four passive secondary dampers are replaced with MR dampers is tested on the roller rig experimental platform. The MR dampers are installed between the body of the car and the bogie, as shown in Fig.24. The irregularity of the high speed train mounted on the roller rig is excited by the vertical and lateral motion under servo control. The accelerometers are attached to the bogie to measure the transverse acceleration and characterize the vibration and critical speed of the train. The output terminals of the accelerometers are connected with a charge amplifier and the data measured by accelerometers are amplified by the charge amplifier and then processed and transferred to the computer. The MRF damper controller is connected with the current driver. The desired current signal generated by the damper controller is delivered to the current drivers. The output terminal of the current drivers is connected with the MRF dampers such that, based on the current signal generated by the damper controller, the current drivers can adjust the input current of the MR valve to control the magnetic field intensity of the MRF damper. With this variation in the intensity of magnetic field, the damping force is changed. 


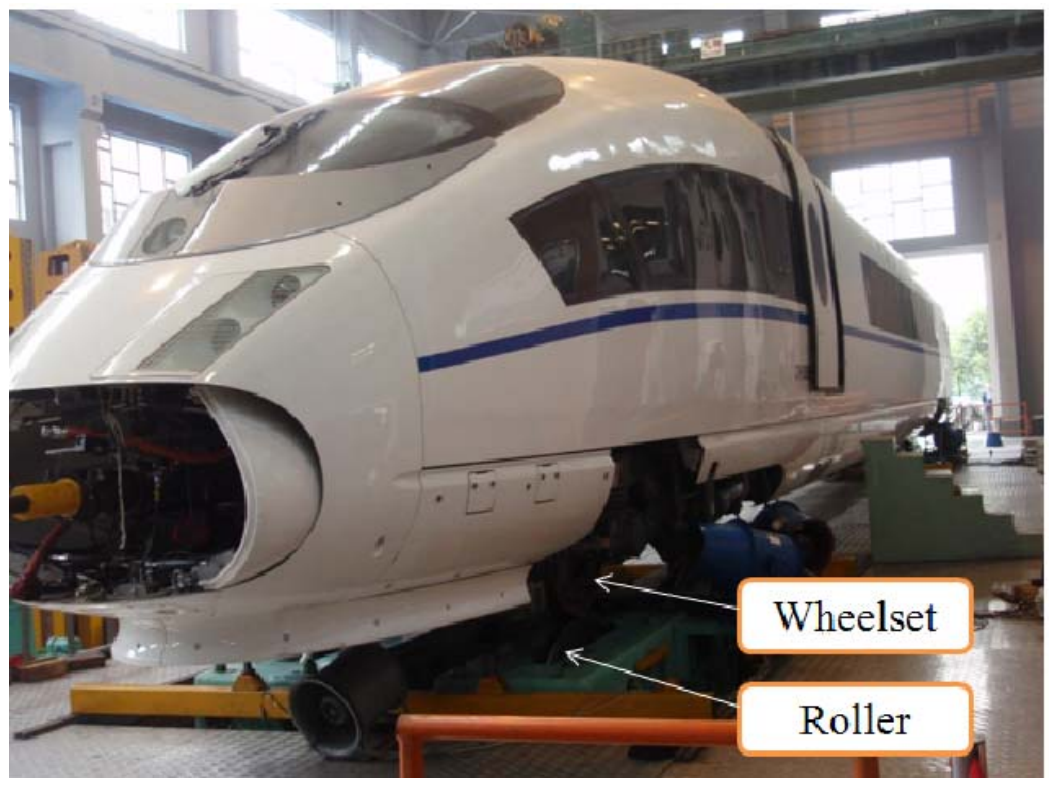

Fig.23 High-speed railway vehicle

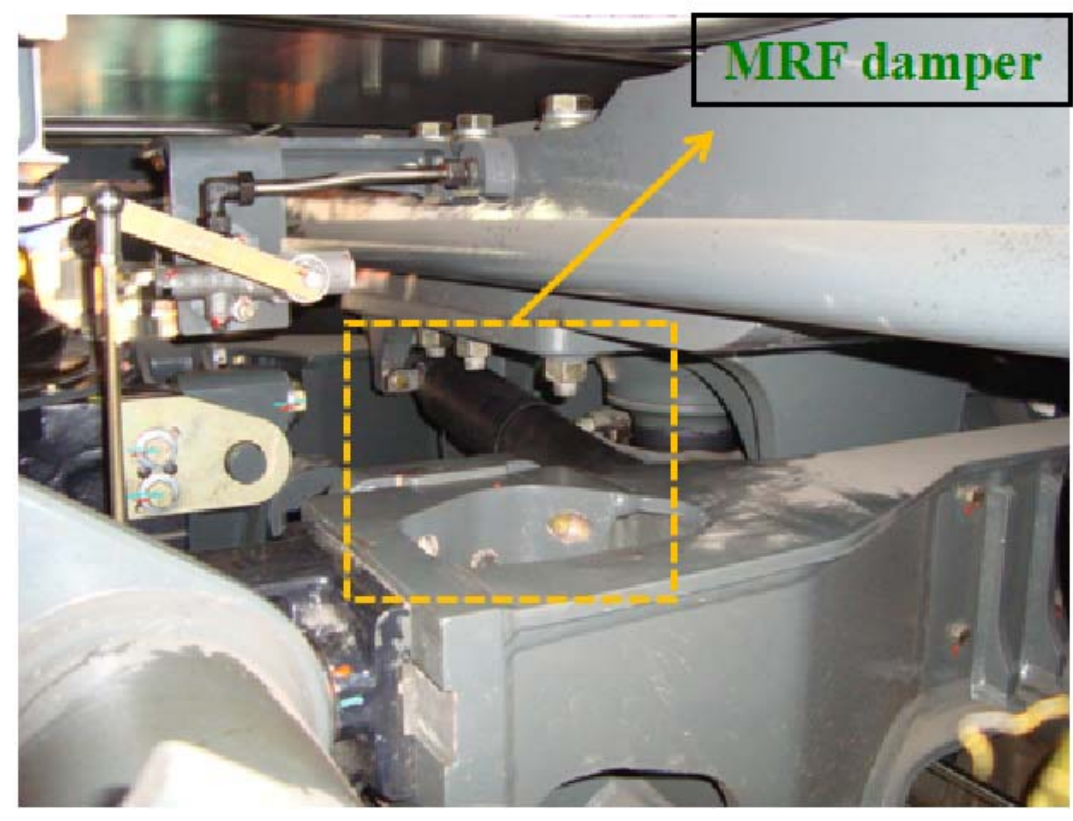

Fig.24 Installation of MR dampers

\subsection{Results of experiment}

In this test the $\mathrm{c}$, control current is changed from 0 to $1.5 \mathrm{~A}$ to realize the change in damping. The train runs at $350 \mathrm{~km} / \mathrm{h}, 320 \mathrm{~km} / \mathrm{h}, 240 \mathrm{~km} / \mathrm{h}$, and $200 \mathrm{~km} / \mathrm{h}$ respectively to investigate the influence of the MRF damper on vibration at different train speeds. The result of the test is shown in Fig.25. It is noticed that the acceleration of the bogie 
changes slightly from $10 \mathrm{~g}$ to $11 \mathrm{~g}$ when the train runs at $200 \mathrm{~km} / \mathrm{h}, 240 \mathrm{~km} / \mathrm{h}$, and 320 $\mathrm{km} / \mathrm{h}$, indicating that the train keeps stable when the acceleration of the bogie varies between $10 \mathrm{~g}$ to $11 \mathrm{~g}$. However, when the train runs at $350 \mathrm{~km} / \mathrm{h}$ and the current of MRF damper is 0 , the bogie acceleration reaches a high level of $13.25 \mathrm{~g}$. In this case the train loses its stability and reaches its critical speed. However, the bogie acceleration decreases continuously when the suspension damping increases by enhancing the current in the MRF damper.

Based on above analysis, the train reaches its critical speed of $350 \mathrm{~km} / \mathrm{s}$ when the current of MRF damper varies from 0 to $0.6 \mathrm{~A}$. As the current increases to $0.8 \mathrm{~A}$, the transverse acceleration of bogie will drop to $10.1 \mathrm{~g}$, which means the train would be stable running at $350 \mathrm{~km} / \mathrm{s}$ and its critical speed will be higher than $350 \mathrm{~km} / \mathrm{s}$. Upon on the comprehensive analysis, it is naturally concluded that the MRF damper possesses the priority to improve the train's stability and enhance train critical speed compared to the passive dampers.

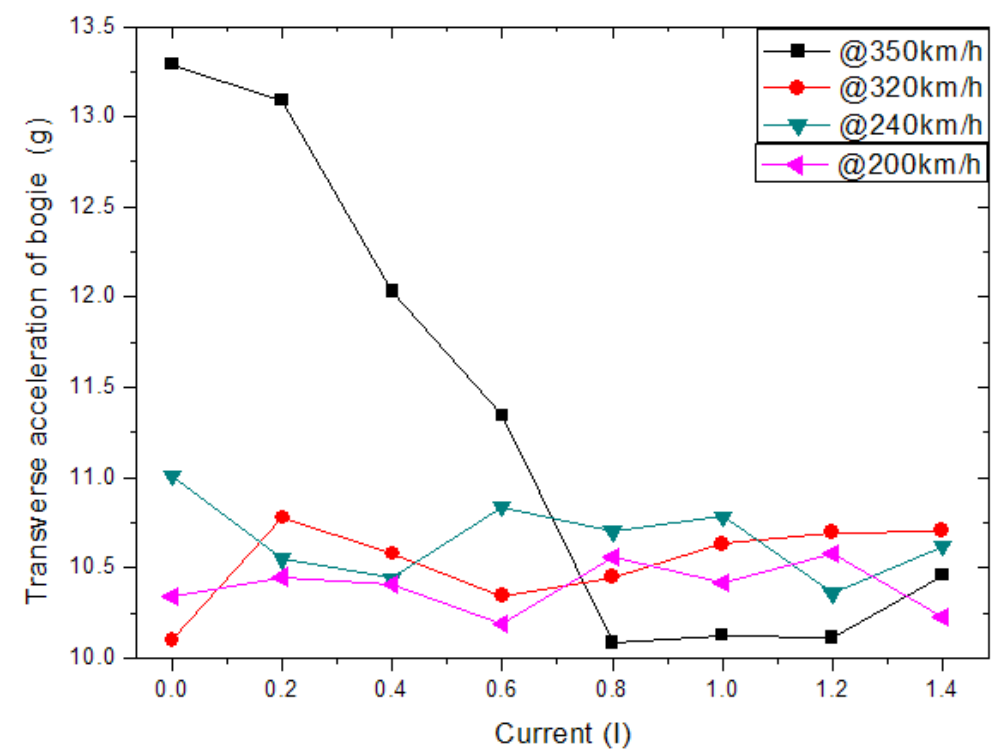

Fig.25 RMS of lateral acceleration of the bogie

\section{Conclusion}

In this article the governing equations of a 15 DOF high-speed train are developed. The damping ratio of each train DOF and the critical speed of high-speed trains are 
calculated based on the train dynamic equations. The results reveal that the train critical speed is mainly dominated by the truck frame and the rear truck wheelsets. The sensitivity of the critical speed with respect to the suspension parameters is computed to analyze the different effect of bogie parameters on the train critical speed. The results indicate that the secondary lateral damping and primary longitudinal stiffness are the two most sensitive parameters impacting the critical speed. Then a high-speed train whose secondary dampers are replaced by MRF dampers is simulated by a combined simulation of ADAMS and MATLAB. The results of this simulation indicate that the MRF damper significantly improve the train critical speed. The results of the experiment also verify the semi-active dampers' ability to improve the train's stability and critical speed.

\section{Acknowledgements}

This work is supported by the University of Wollongong and China Scholarship Council joint scholarships, National Natural Science Foundation of China (grant no.51205100, and 51328502), and the Hong Kong Polytechnic University Interdisciplinary Research Project (grant no.4-BC01). 


\section{Appendix A.}

Table A.1. Nomenclature of train dynamic model symbol

\begin{tabular}{|c|c|}
\hline Symbol & Definition \\
\hline$m_{\omega}$ & Mass of wheelset \\
\hline$I_{\omega \mathrm{X}}$ & Roll moment of inertia of wheelset \\
\hline$I_{\text {Фy }}$ & Pitch moment of inertia of wheelset \\
\hline$I_{\omega \mathrm{ZZ}}$ & Yaw moment of inertia of wheelset \\
\hline$r_{0}$ & Centred wheel rolling radius \\
\hline$m_{\mathrm{t}}$ & Mass of truck \\
\hline$I_{\mathrm{tx}}$ & Roll moment of inertia of truck \\
\hline$I_{\mathrm{ty}}$ & Pitch moment of inertia of truck \\
\hline$I_{\mathrm{tz}}$ & Yaw moment of inertia of truck \\
\hline$m_{\mathrm{c}}$ & Mass of car body \\
\hline$I_{\mathrm{cx}}$ & Roll moment of inertia of car body \\
\hline$I_{\mathrm{cy}}$ & Pitch moment of inertia of car body \\
\hline$I_{\mathrm{cz}}$ & Yaw moment of inertia of car body \\
\hline$k_{\mathrm{px}}$ & Primary longitudinal stiffness \\
\hline$k_{\mathrm{py}}$ & Primary lateral stiffness \\
\hline$k_{\mathrm{pz}}$ & Primary vertical stiffness \\
\hline$c_{\mathrm{py}}$ & Primary lateral damping \\
\hline$c_{\mathrm{pz}}$ & Primary vertical damping \\
\hline$k_{\mathrm{sy}}$ & Secondary lateral stiffness \\
\hline$k_{\mathrm{sz}}$ & Secondary vertical stiffness \\
\hline$c_{\mathrm{sy}}$ & Secondary lateral damping \\
\hline$c_{\mathrm{sz}}$ & Secondary vertical damping \\
\hline$h_{\mathrm{ts}}$ & $\begin{array}{l}\text { Vertical distance from truck frame centre of } \\
\text { gravity to secondary suspension }\end{array}$ \\
\hline$h_{\mathrm{cs}}$ & $\begin{array}{l}\text { Vertical distance from car body centre of gravity } \\
\text { to secondary suspension }\end{array}$ \\
\hline$h_{\mathrm{tp}}$ & $\begin{array}{l}\text { Vertical distance from truck frame centre of } \\
\text { gravity to primary suspension }\end{array}$ \\
\hline$h_{\mathrm{wp}}$ & $\begin{array}{l}\text { Vertical distance from primary suspension to } \\
\text { truck frame centre of gravity }\end{array}$ \\
\hline$l$ & Half of truck centre pin spacing \\
\hline$b$ & Half of wheelbase \\
\hline$a$ & Half of wheelset contact distance \\
\hline$d_{\mathrm{p}}$ & Half of primary spring lateral distance \\
\hline$d_{\mathrm{s}}$ & Half of secondary suspension spacing \\
\hline$v$ & The travelling speed of the vehicle train \\
\hline$f_{11}$ & Lateral creep coefficient \\
\hline
\end{tabular}


Table A.1 continue

\begin{tabular}{l|l}
\hline Symbol & Definition \\
\hline$f_{22}$ & Spin creep coefficient \\
$l_{\mathrm{c}}$ & Total length of car body \\
$l_{\mathrm{b}}$ & Half distance of two truck center \\
$h_{4}$ & Vertical distance from car body center of gravity \\
& to secondary springs \\
$k_{\mathrm{c}}$ & Contact stiffness \\
$\delta$ & Effective wheel conicity \\
\hline
\end{tabular}

Table A.2. Nomenclature of critical speeds of each DOF

\begin{tabular}{l|l}
\hline Symbol & Definition \\
\hline $\mathrm{C}_{\mathrm{fl}}$ & Critical speed of front truck frame lateral motion \\
$\mathrm{C}_{\mathrm{fy}}$ & Critical speed of front truck frame yaw motion \\
$\mathrm{C}_{\mathrm{rl}}$ & Critical speed of rear truck frame lateral motion \\
$\mathrm{C}_{\mathrm{ry}}$ & Critical speed of rear truck frame yaw motion \\
$\mathrm{C}_{\mathrm{rll}}$ & Critical speed of rear truck leading wheelset \\
& lateral motion \\
$\mathrm{C}_{\mathrm{rly}}$ & Critical speed of rear truck leading wheelset yaw \\
& motion \\
$\mathrm{C}_{\mathrm{rtl}}$ & Critical speed of rear truck trailing wheelset \\
& lateral motion \\
$\mathrm{C}_{\mathrm{rty}}$ & Critical speed of rear truck trailing wheelset yaw \\
& motion \\
$\mathrm{C}_{\mathrm{fty}}$ & Critical speed of front truck trailing wheelset \\
& yaw motion \\
\hline
\end{tabular}

\section{References}

[1] M. Givoni, Development and Impact of the Modern High-speed Train: A Review, Transport Reviews, A Transnational Transdisciplinary Journal 26 (2006) 593-611.

[2] C.E. Hanson, J.C. Ross, D.A. Towers, High-speed ground transportation noise and vibration impact assessment, (2012) 1-235, Report.

[3] R.S. Raghunathan, H. Kim, D.T. Setoguchi, Aerodynamics of High-Speed Railway train, Progress in Aerospace Sciences 38 (2002) 469-514.

[4] J. Han, Y. Hayashi, P. Jia, Q. Yuan, Economic Effect of High-Speed Rail: Empirical Analysis of Shinkansens Impact on Industrial Location, Journal of Transportation Engineering 138 (2012) 1551-1557.

[5] K. SASAKI, A Lateral Semi-Active Suspension of Tilting Train, Quarterly Report of RTRI $41(2000)$ 11-15. 
[6] A.H. Wickens, The dynamics of railway vehicles-from stephenson to carter, Proceedings of the Institution of Mechanical Engineers 212 (1998) 209-217.

[7] S.Y. Lee, Y.C. Cheng, Cheng, Nonlinear Analysis on Hunting Stability for High-Speed Railway Vehicle Trucks on Curved Tracks, Transactions of the ASME 127 (2005) 324-332.

[8] H. Scheffel, R.D.Fröhling,P.S. Heyns, Curving and Stability Analysis of Self-Steering Bogies Having A Variable Yaw Constraint, Vehicle System Dynamics Proc. of 13th (1993).

[9] A.H. Wickens, Railway Vehicles With Generic Bogies Capable of Perfect Steering, Vehicle System Dynamics 25 (1996) 389-412.

[10] $\mathrm{H}$. $\mathrm{Wu}, \mathrm{P}$. Wu Effect of equipment suspension stiffness on riding quality, Noise and Vibration Control 4 (2012) 3-77.

[11] H. Liu, J. Zeng, Study on ride comfort of train system, China Railway Science 25 (2004) 20-25.

[12] J. Zeng, T. Xu, New method to determine the linear and nonlinear train critical speed, High-speed Train 38 (2000) 1-3.

[13] D. Zhang, Dynamics of track-train system, China Railway Publishing House, Beijing (1996).

[14] R.M. Goodall, Control Engineering Challenges for Railway Trains of the Future, Measurement and Control 44(1) (2011) 16-24.

[15] J. Perez, J.M. Busturia, R.M. Goodall, Control strategies for active steering of bogie-based railway vehicles, Control Engineering Practice 10(9) (2002)1005-1012.

[16] E.M. Elbeheirym, D.C. Karnopp, Optimal control of vehicle random vibration with constrained suspension deflection, Journal of Sound and Vibration 189(5) (1996) 547-564.

[17] T.J. Gordona, Non-linear optimal control of a semi-active vehicle suspension system, Chaos, Solitons and Fractals 5(9) (1995) 1603-1617.

[18] Y.J. Shin, W.H. You, H.M. Hur, J.H. Park, Semi-active control to reduce carbody vibration of railway vehicle by using scaled roller rig, Journal of mechanical science and technology 26 (2012) 3423-3431.

[19] C. Spelta, S.M. Savaresi, F. Codec, M. Montiglio, M. Ieluzzi, Smart-Bogie: Semi-Active Lateral Control of Railway Vehicles, Asian Journal of Control 14 (2012) 875-890.

[20] L.H. Zong, X.L. Gong, S.H. Xuan, C.Y. Guo, Semi-active H control of high-speed railway vehicle suspension with magnetorheological dampers, Vehicle System Dynamics (2013) 1-27.

[21] H.R. ONeill, G.D. Wale, Semi-active suspension improves rail vehicle ride, Computing $\delta$ control engineering journal 5(4) (1994) 183-188.

[22] F. Gordaninejad, X. Wang, G. Hitchcock, K.K. et al., Controllable magneto-rheological fluid devices for motion-damping, US Patent Specification7, 364 (2008).

[23] G.H. Hitchock, X. Wang, F. Gordaninejad, A new bypass magnetorheological fluid damper, Journal of Vibration and Acoustics-Transactions of the ASME 129 (2007) 
641-647.

[24] H. Deng, X. Gong, L. Wang, Development of an adaptive tuned vibration absorber with magnetorheological elastomer, Smart materials and structures 15 (2006) N111-N116.

[25] X.Z. Zhang, W.H. Li, Adaptive tuned dynamics vibration absorbers working with MR elastomers, Smart Structures and Systems 5 (2009) 517-529.

[26] H. Du, W. Li, N. Zhang, Vibration Control of Vehicle Seat Integrating with Chassis Suspension and Driver Body Model, Advances in Structural Engineering 16 (2013) 1-10.

[27] W. Li, X. Zhang, H. Du, Development and simulation evaluation of a magnetorheological elastomer isolator for seat vibration control, Journal of Intelligent Material Systems and Structures 23 (2012) 1041-1048.

[28] D.H. Wang, W.H. Liao, Semi-active suspension systems for railway vehicles using magnetorheological dampers. Part I: system integration and modeling, Vehicle System Dynamics 47 (2009) 1305-1325.

[29] D.H. Wang, W.H. Liao, Semi-active suspension systems for railway vehicles using magnetorheological dampers. Part II: simulation and analysis, Vehicle System Dynamics 47 (2009) 1439-1471.

[30] H.Y. Liu, Study on the key dynamic problem in high-speed train, PhD Thesis, Southwest Jiaotong University, Chengdu (2003).

[31] V.K. Garg, Dynamics of railway vehicle systems, Academic press, Toronto (1984).

[32] A. Khludnev, A. Novotny, J. Sokolowski, A. zochowski, Shape and topology sensitivity analysis for cracks in elastic bodies on boundaries of rigid inclusions, Journal of the Mechanics and Physics of Solids 57 (2009) 17181732.

[33] S. Giusti, A. Novotny, E. de Souza Neto, R. Feijóo, Sensitivity of the macroscopic elasticity tensor to topological microstructural changes, Journal of the Mechanics and Physics of Solids 57 (2009) 555-570.

[34] J.H. Jang, C.S. Han, The state sensitivity analysis of the front wheel steering vehicle: in the time domain, KSME International Journal 11 (1997) 595-604.

[35] T. Park, C. Han, J. Jang, Dynamic sensitivity analysis for the pantograph of a high-speed rail vehicle, Journal of Sound and Vibration 266 (2003) 235-260.

[36] G Yang, Large-scale magnetorheological fluid damper for vibration mitigation: modeling, testing and control, PhD Thesis, University of Notre Dame, South Bend (2001). 